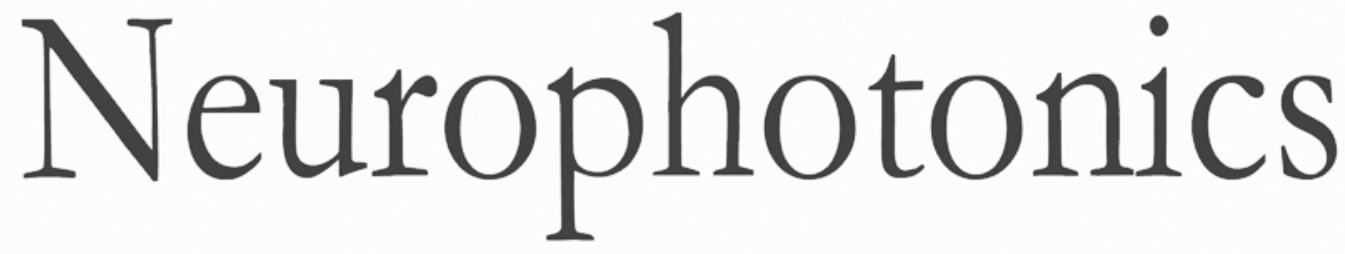

\title{
Relationship between relative cerebral blood flow, relative cerebral blood volume, and relative cerebral metabolic rate of oxygen in the preterm neonatal brain
}

Mina Nourhashemi

Guy Kongolo

Mahdi Mahmoudzadeh

Sabrina Goudjil

Fabrice Wallois 


\title{
Relationship between relative cerebral blood flow, relative cerebral blood volume, and relative cerebral metabolic rate of oxygen in the preterm neonatal brain
}

Mina Nourhashemi, Guy Kongolo, Mahdi Mahmoudzadeh, Sabrina Goudjil, and Fabrice Wallois*

Université de Picardie, INSERM U 1105, GRAMFC, CHU Sud, rue René Laennec, 80054 Amiens Cedex 1, France

\begin{abstract}
The mechanisms responsible for coupling between relative cerebral blood flow ( $\mathrm{rCBF}$ ), relative cerebral blood volume ( $\mathrm{rCBV}$ ), and relative cerebral metabolic rate of oxygen $\left(\mathrm{rCMRO}_{2}\right)$, an important function of the microcirculation in preterm infants, remain unclear. Identification of a causal relationship between rCBF-rCBV and $\mathrm{rCBF}-\mathrm{rCMRO}_{2}$ in preterms may, therefore, help to elucidate the principles of cortical hemodynamics during development. We simultaneously recorded $\mathrm{rCBF}$ and $\mathrm{rCBV}$ and estimated $\mathrm{rCMRO}_{2}$ by two independent acquisition systems: diffuse correlation spectroscopy and near-infrared spectroscopy, respectively, in 10 preterms aged between 28 and 35 weeks of gestational age. Transfer entropy was calculated in order to determine the directionality between $\mathrm{rCBF}-\mathrm{rCBV}$ and $\mathrm{rCBF}-\mathrm{rCMRO}_{2}$. The surrogate method was applied to determine statistical significance. The results show that $\mathrm{rCBV}$ and $\mathrm{rCMRO}_{2}$ have a predominant driving influence on rCBF at the resting state in the preterm neonatal brain. Statistical analysis robustly detected the correct directionality of rCBV on rCBF and $\mathrm{rCMRO}_{2}$ on $\mathrm{rCBF}$. This study helps to clarify the early organization of the $\mathrm{rCBV}_{-} \mathrm{rCBF}$ and $\mathrm{rCBF}-\mathrm{rCMRO}_{2}$ inter-relationship in the immature cortex. ๑ 2017 Society of Photo-Optical Instrumentation Engineers (SPIE) [DOI: 10.1117/1.NPh.4.2.021104]
\end{abstract}

Keywords: relative cerebral blood flow; relative cerebral blood volume; relative cerebral metabolic rate of oxygen; near-infrared spectroscopy; diffuse correlation spectroscopy; transfer entropy.

Paper 17001SSR received Jan. 13, 2017; accepted for publication Mar. 30, 2017; published online Apr. 18, 2017.

\section{Introduction}

Coupling between cerebral blood flow (CBF), cerebral blood volume (CBV), and cerebral metabolic rate of oxygen $\left(\mathrm{CMRO}_{2}\right)$ is an important primary function of the microcirculation, ${ }^{1,2}$ as the brain requires a continuous supply of glucose and oxygen $\left(\mathrm{O}_{2}\right)$ provided by $\mathrm{CBF}$ and blood oxygen content to meet cellular oxygen requirements. ${ }^{2}$ Identification of a causal relationship between relative cerebral blood volume (rCBV),-relative cerebral blood flow (rCBF), and relative cerebral metabolic rate of oxygen $\left(\mathrm{rCMRO}_{2}\right)-\mathrm{rCBF}$ under resting physiological conditions in the neonatal brain could help to elucidate the principles of cortical hemodynamic function during development.

High coupling between changes in CBF and CBV has been demonstrated in both resting state and stimulus-induced activity. The relationship between CBF and CBV has been shown to be adequately quantified by a simple power law equation in both steady state and dynamic state [Grubb's law, which assumes a constant relationship between $\mathrm{rCBF}$ and $\mathrm{rCBV}$ : $\mathrm{rCBV}=$ $\left.(\mathrm{rCBF})^{1 / \beta}\right] .{ }^{3}$ Several groups have observed different values of $\beta$ when measured during functional challenges. ${ }^{4}$ Under steadystate conditions, CBF and CBV have been shown to have steady values in response to a physiological challenge, such as hypercapnia or hypocapnia. ${ }^{3,5}$ Grubb's exponent has often been measured under dynamic conditions during neural stimulation experiments, in which both CBF and CBV changed following stimulation. ${ }^{4}$ Previous stimulation studies have reported that $\mathrm{CBV}$ increased progressively during the first few seconds of

*Address all correspondence to: Fabrice Wallois, E-mail: Fabrice.wallois@ u-picardie.fr stimulation, while $\mathrm{CBF}$ did not change. After several seconds, $\mathrm{CBF}$ started to increase much more rapidly than $\mathrm{CBV}$ and returned to baseline before $\mathrm{CBV}$ returned to baseline. ${ }^{6,7}$ Under resting-state conditions, the causality and nonlinear relationship between $\mathrm{CBF}$ and $\mathrm{CBV}$ changes can be used to determine whether CBV drives CBF or vice versa.

Roy and Sherrington ${ }^{1}$ proposed the hypothesis of stimulusinduced increases in CBF driven by local metabolic demand. Strong coupling between $\mathrm{CBF}$ and $\mathrm{CMRO}_{2}$ is observed during neural stimulation in adults, ${ }^{8}$ but a mismatch in CBF-metabolism coupling was reported by Fox and Raichle, ${ }^{9}$ who described that, during neuronal activation, regional CBF increased by $50 \%$, while $\mathrm{CMRO}_{2}$ increased by only $5 \%$. In fact, $\mathrm{CBF}$ can increase in the absence of any significant variations of $\mathrm{CMRO}_{2},{ }^{10}$ and inversely, $\mathrm{CMRO}_{2}$ can increase with no significant increase of $\mathrm{CBF}^{11}$ Whether or not a precise coupling exists between $\mathrm{CBF}$ and $\mathrm{CMRO}_{2}$ during neural stimulation has been the subject of numerous studies in both adults ${ }^{12}$ and preterms. ${ }^{13,14}$ While the linear relationship between $\mathrm{CBF}$ and $\mathrm{CMRO}_{2}$ changes at the resting state has been demonstrated in adults, ${ }^{1}$ it remains a subject of debate in preterms. ${ }^{15}$ This study was designed to address whether $\mathrm{rCBV}$ drives $\mathrm{rCBF}$ in preterms or vice versa and to provide information about the directionality and causality between measured changes in $\mathrm{rCBV}$ and $\mathrm{rCBF}$ (also between evaluated $\mathrm{rCMRO}_{2}$ and $\mathrm{rCBF}$ ).

We used the transfer entropy (TE) method based on information theory ${ }^{16}$ to evaluate the nonlinear interactions between $\mathrm{rCBV}-\mathrm{rCBF}$ and $\mathrm{rCBF}-\mathrm{rCMRO}_{2}$ in resting preterm infants. TE determines the intensity and direction of the relationship 
and the dominance between two discrete random variables ${ }^{17}$ (i.e., $\mathrm{rCBF}$ and $\mathrm{rCMRO}_{2}$ ). Based on the concept of causality, ${ }^{18}$ we investigated a possible causal interaction between $\mathrm{rCBF}$ and $\mathrm{rCBV}$ by predictive analysis of time-series of $\mathrm{rCBF}$ (or $\mathrm{rCBV}$ ) measurements by incorporating data from another previous rCBV (or rCBF) time-series.

Near-infrared spectroscopy (NIRS) ${ }^{19}$ and diffuse correlation spectroscopy (DCS $)^{20}$ are optical imaging techniques that noninvasively and repeatedly measure cerebral vascular parameters at the bedside in preterms. ${ }^{21,22}$ An NIRS device allows the monitoring of relative changes in $([\mathrm{HbT}]([\mathrm{HbO}]+[\mathrm{Hb}])$ that is equivalent to relative changes in $\mathrm{CBV}$. The relative changes in $\mathrm{CBF}$ are proportional to the relative changes in tissue blood flow related to the motion of red blood cells that can be measured by the DCS device. ${ }^{20}$

Estimation of $\mathrm{rCMRO}_{2}$ by optical imaging requires measurement of rCBF and oxygen extraction fraction (OEF). According to Boas and Payne, ${ }^{23} \mathrm{CBF}$ can be estimated from CBV by inverting Grubb's equation, which allows $\mathrm{CMRO}_{2}$ to be estimated from $\mathrm{CBV}$. To evaluate $\mathrm{rCMRO}_{2}$ independently from $\mathrm{rCBF}$, it required the calculation of $\mathrm{rCMRO}_{2}$ by $\mathrm{rCBV}$ and $\mathrm{OEF}$. This can be achieved due to the independent measurement of rCBV by NIRS and rCBF by DCS. Although Leung et al. ${ }^{24}$ suggested that Grubb's relation cannot be inverted to estimate $\mathrm{CBF}$ from $\mathrm{CBV}$. Using independent estimation of $\mathrm{rCMRO}_{2}$ by $\mathrm{rCBV},{ }^{25}$ the causality investigation could be performed by analyzing the interactions between estimated $\mathrm{rCMRO}_{2}$ (NIRS) and directly measured $\mathrm{rCBF}$ (DCS). $\mathrm{rCBF}$ and $\mathrm{rCMRO}_{2}$ are linked in a complex way, notably they are affected by autoregulation mechanisms. ${ }^{26}$ These adaptive mechanisms act to preserve constant CBF over a range of blood pressures by adapting cerebrovascular resistances or vasodilation. The mechanisms of cerebral autoregulation in preterm infants remain unclear and may involve a combination of myogenic, neurogenic, and metabolic processes that regulate cerebrovascular resistance to maintain $\mathrm{CBF}^{26}$ In the present study, we evaluate the possible relationships and causalities between $\mathrm{rCBF}, \mathrm{rCBV}$, and $\mathrm{rCMRO}_{2}$ in resting state in preterms.

\section{Materials and Methods}

Ten preterm neonates [six females; mean gestational age (GA) at birth: 28.5 weeks GA and four males; mean GA at birth: 27.5 weeks GA] were tested in the supine position (recording age: 31 wGA, Table 1). This study is part of the French public hospital Clinical Research Project (PHRC National). The study was approved by the Amiens University Hospital local ethics committee according to the guidelines of the Declaration of Helsinki of 1975 (CPP Nord-Ouest II-France IDRCB-2008-A00704-51). Parents were informed about the study and provided their written informed consent.

\subsection{Diffuse Correlation Spectroscopy and Near- Infrared Spectroscopy Instrumentation}

DCS and NIRS devices were synchronized and all events detected by DCS were also recorded by the NIRS devices (Fig. 1). The overall measurement duration was between 30 and $40 \mathrm{~min}$ for each subject. NIRS/DCS data were acquired simultaneously from the frontal area providing large volumes of data in order to converge TE and investigate the relationships between $\mathrm{rCBF}-\mathrm{rCBV}$ and $\mathrm{rCBF}-\mathrm{rCMRO}_{2}$ at the resting state.

\subsubsection{Diffuse correlation spectroscopy}

DCS is an optical blood flow measurement modality that uses intensity fluctuations of NIR light to noninvasively quantify CBF. The light scattered by moving red blood cells causes temporal fluctuation of the detected light intensity. The time lag of these fluctuations is quantified by the intensity-time autocorrelation function of the detected light. The correlation diffusion equation is applied to fit the autocorrelation function in order to calculate a cerebral blood flow index (CBFi). Neuro-MonitorFloMo (Hemophotonics SL, Spain) consists of a narrowband continuous-wave (CW) laser (785 nm, Crystalaser Inc., Nevada) with a long coherence length $(>50 \mathrm{~m})$, four fast photon-counting avalanche photodiodes (SPCM-AQR-14-FC, Pacer Components Inc., United Kingdom), and a four-channel autocorrelator board (Flex03OEM-4CH, Correlator Inc., New Jersey). The system uses CW lasers in the NIR range $(\sim 785 \mathrm{~nm})$ with an acquisition rate of $0.3921 \mathrm{~Hz}$ (one sample every $2.55 \mathrm{~s}$ ). The light was delivered to the brain surface via multimode fibers and light on the head surface was detected by four single-mode fibers $d_{\text {DCS }}=2 \mathrm{~cm}$ away from the source. The light was detected by single-photon counting avalanche photodiodes (SPCM-AQR $(\mathrm{H})$ series, Excelitas, Canada).

\subsubsection{Continuous-wave tissue oximeter (near-infrared spectroscopy)}

NIRS probes NIRO-200NX (Hamamatsu Photonics Corp., Tokyo, Japan) were placed on the infant's forehead to measure cerebral oxygenation in the frontal cortex. The NIRO 200 NX uses spatially resolved spectroscopy (SRS) at three wavelengths ( $\lambda=735,810$, and $850 \mathrm{~nm})$. It is based on the solution of the diffusion approximation for a highly scattering semi-infinite homogeneous medium. The effective light attenuation coefficient can be estimated by measuring the decrease in reflected light as a function of distance. By assuming wavelength dependence of the reduced scattering coefficient, the spectral shape of the absorption coefficient can then be calculated and tissue oxygen saturation can be estimated. ${ }^{27}$ The average output power of the lasers was $<2 \mathrm{~mW}$ and the $\mathrm{CW}$ acquisition rates were $5 \mathrm{~Hz}$ (200 ms).

\subsubsection{Diffuse correlation spectroscopy and near-infrared spectroscopy probe}

To simultaneously measure $\mathrm{rCBF}$ and $\mathrm{rCBV}$ dynamics, we developed a specific probe that supports DCS, and NIRS emitters and detectors. Recording sites on the subject's head and a diagram of the two combined probes are shown in Fig. 1(a). The infants were placed in the supine position on a comfortable pad in a dark and quiet incubator. The incubator was further protected against ambient light by dark sheets. The probe was smoothly secured to the infant's head with straps and foam padding. Figure 1(b) shows the diagram of the combined DCSNIRS probe. DCS probe: The tips of the source and detector fibers were angled to $90 \mathrm{deg}$ and tightly held in place by a flexible rubber material. Four detectors (blue circles) were set up in a multicore arrangement away $\left(d_{\mathrm{DCS}}=2 \mathrm{~cm}\right)$ from the emitter (red circle), creating four measuring points (channels) over the frontal area. A special DCS probe made of soft, flexible rubber (3 $\mathrm{mm}$ thick) was designed to comfortably hold the source and detector fibers on the infant's head. NIRS probe: The NIRS probe comprising two detectors and one source and the 
Nourhashemi et al.: Relationship between relative cerebral...

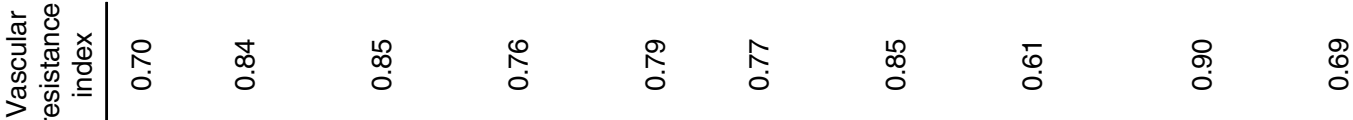

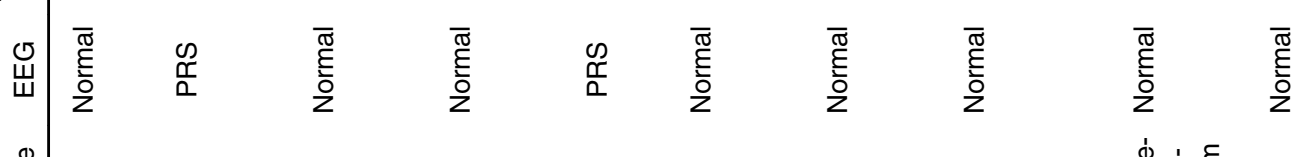

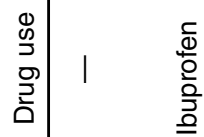

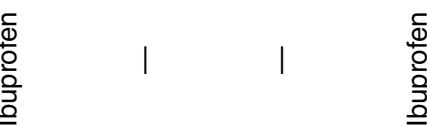

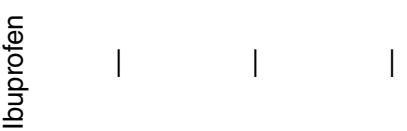

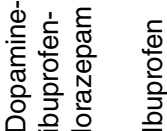

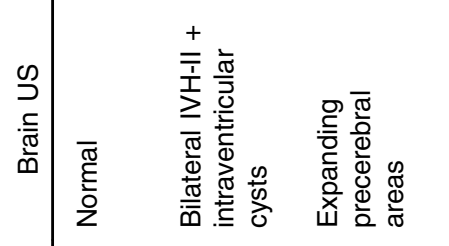

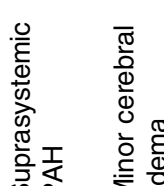

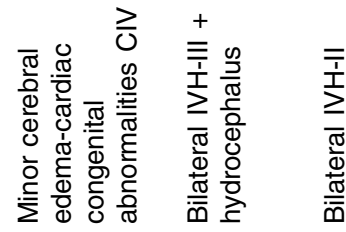

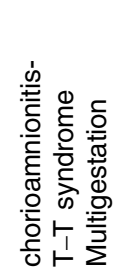

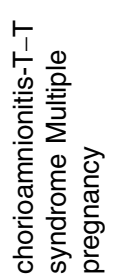

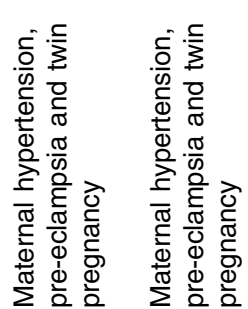

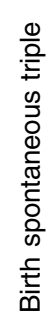

要

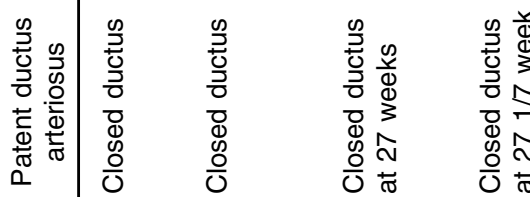

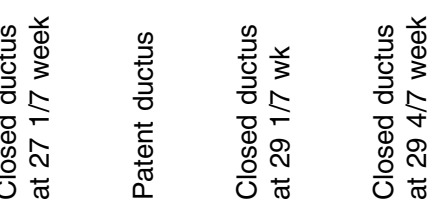

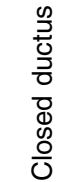

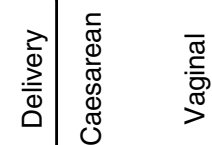

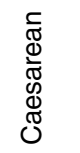

ᄃ

胥

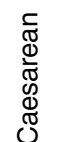

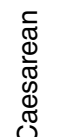

产产产

흥

$\stackrel{\infty}{\circ}$

$\stackrel{\infty}{>}$

요

$\stackrel{\infty}{\varnothing}$

$\stackrel{\infty}{>} \stackrel{\infty}{>}$

量题

홍

$<5$

苾

$\stackrel{\infty}{\stackrel{\infty}{N}}$

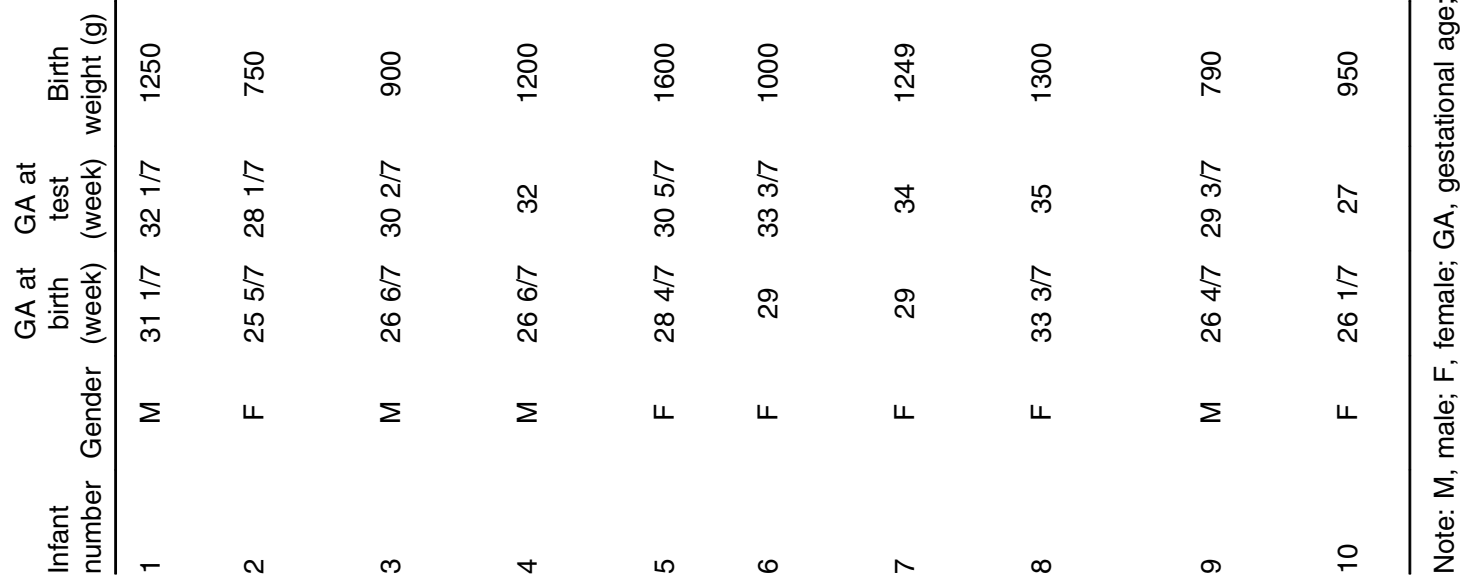

Neurophotonics 


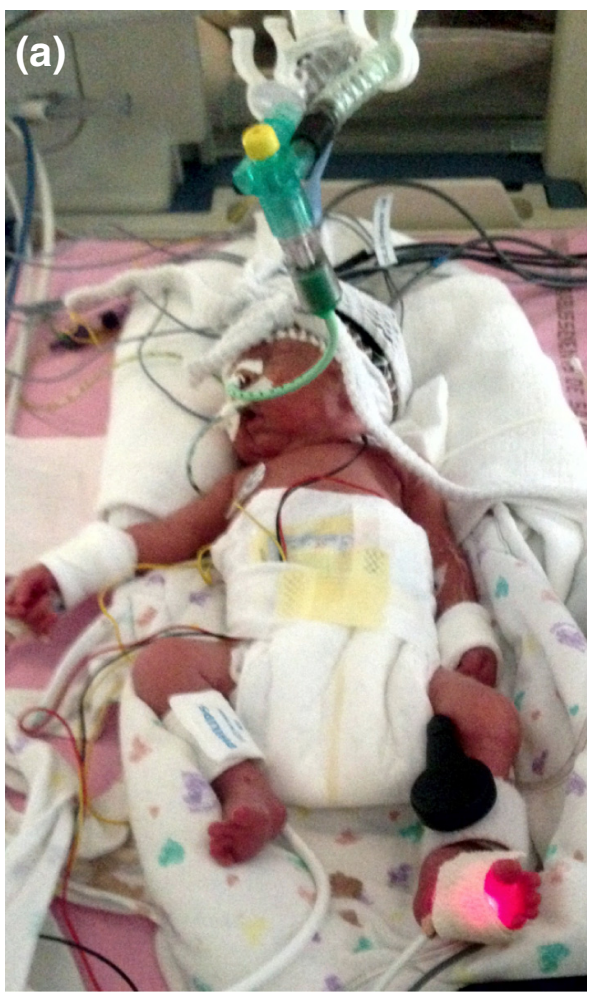

(b)

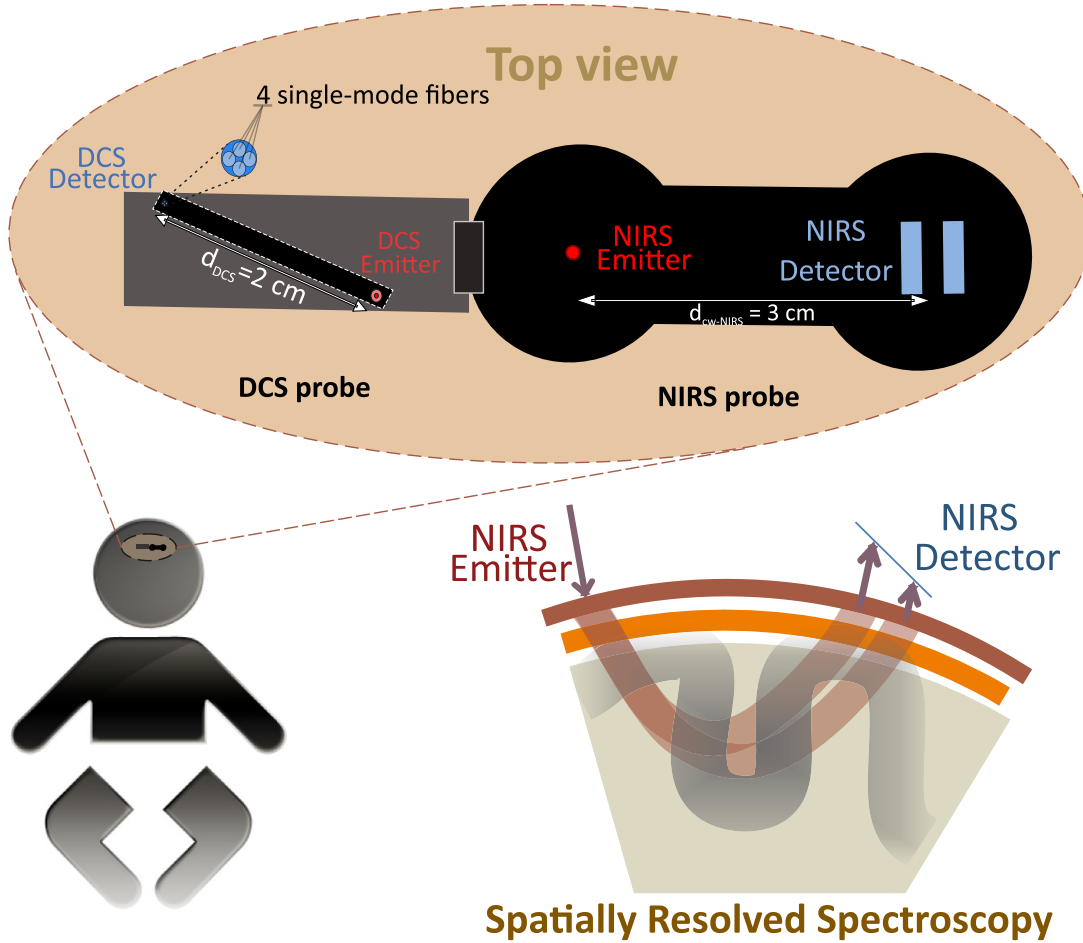

(c)
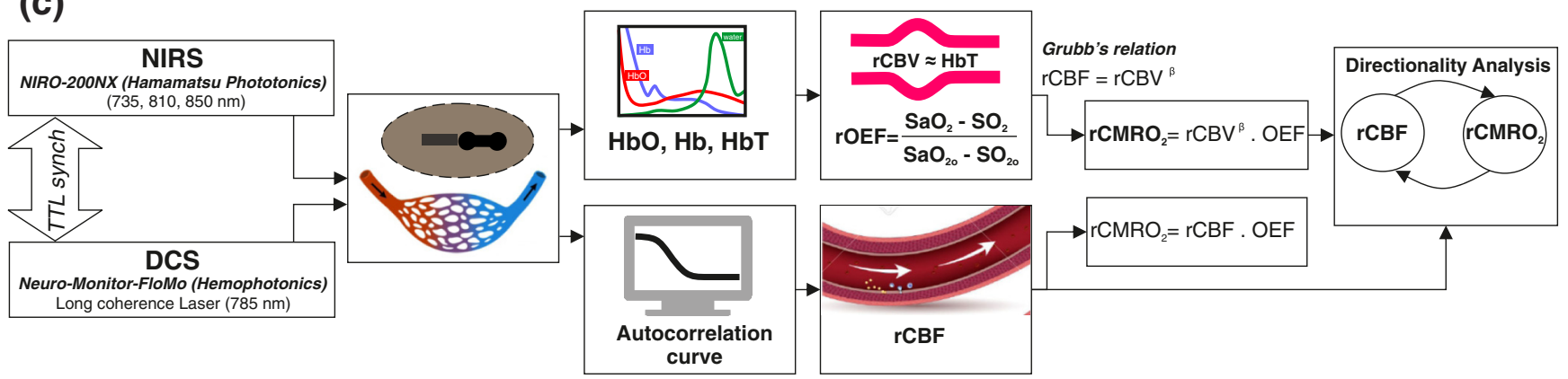

Fig. 1 (a) The infants were tested with the DCS and CW-NIRS systems, (b) diagram of the combined DCS-NIRS probe, and (c) diagram of the calculation of $\mathrm{rCMRO}_{2}$ by NIRS data and rCBF by DCS data.

emitter-detector distance of the CW optical NIRS probe was $3 \mathrm{~cm}$. The NIRS source contained three wavelength emitters (735, 810, and $850 \mathrm{~nm}$ ) (bottom right-hand corner). $\mathrm{SO}_{2}$ (tissue oxygenation) was measured by using the SRS method. SRS is a method used to calculate concentrations by measuring the change of light attenuation $(A)$ over distance $(d)$, i.e., $\frac{\partial A}{\partial d}$, as shown in Fig. 1(b).

\subsection{Data Processing and Statistical Analysis}

Offline analysis was performed using in-house MATLAB scripts for $\mathrm{CBF}$ measured by Neuro-Monitor-FloMo (Hemophotonics $\mathrm{SL}$, Spain), and for $\mathrm{CBV}$ (total hemoglobin, $\mathrm{HbT}=\mathrm{HbO}+$ $\mathrm{HbR}$ ) and OEF measured by NIRO-200NX (Hamamatsu Photonics Corp, Tokyo, Japan).

A z-score-based algorithm was used to reject artifact signals. ${ }^{13}$ As individual features, such as skull thickness and hair color, influence signal strength, the signal was first homogenized in each participant by computing a z-score across all measurement periods for each channel. A z-score greater than
4 in any channel was considered to be an artifact, in which case the entire artifact time-window was excised from the data for all channels. ${ }^{13}$ The mean value of rCBF signals recorded from four paired source-detectors was calculated. The remaining cleaned $\mathrm{rCBV}, \mathrm{rCBF}$ signals were bandpass filtered $(0.03$ to $0.5 \mathrm{~Hz}$ ) using a zero phase filter (Butterworth, order: 3 ) to eliminate physiologic noise (e.g., slow drifts, arterial pulse oscillations).

\subsection{1 $\mathrm{rCMRO}_{2}$ calculated by near-infrared spectroscopy data}

$\mathrm{CMRO}_{2}$ can generally be calculated by combining relative changes in $\mathrm{CBF}$ and $\mathrm{OEF}$, but monitoring $\mathrm{rCBV}$ independently of $\mathrm{rCBF}$ by the NIRS device allows $\mathrm{rCMRO}_{2}$ to be evaluated independently of $\mathrm{rCBF}^{21}$ by using $(\mathrm{rCBV})^{\beta}$ instead of $\mathrm{rCBF}$ in relation ${ }^{1}$ [Fig. 1(c)]. The $\mathrm{rCMRO}_{2}$ was estimated as follows: $:^{28}$

$\mathrm{rCMRO}_{2}=\mathrm{rCBF} \times \mathrm{rOEF}$, 
where rOEF is defined as follows:

$\mathrm{rOEF}=\frac{\mathrm{SaO}_{2}(t)-\mathrm{SvO}_{2}(t)}{\mathrm{SaO}_{2}\left(t_{0}\right)-\mathrm{SvO}_{2}\left(t_{0}\right)}=\frac{\mathrm{SaO}_{2}(t)-\mathrm{SO}_{2}(t)}{\mathrm{SaO}_{2}\left(t_{0}\right)-\mathrm{SO}_{2}\left(t_{0}\right)}$

With venous oxygenation, $\mathrm{SvO}_{2}=\left(\mathrm{SO}_{2}-a \times \mathrm{SaO}_{2}\right) / b$, where $a+b=1, a$ and $b$ are the arterial and venous contributions that are constant over time, ${ }^{29}$ and arterial oxygenation $\mathrm{SaO}_{2}=100 \%$. Mechanical ventilation parameters and inspired oxygen concentrations were constantly maintained at sufficiently high levels to saturate arterial hemoglobin $\left(\mathrm{SaO}_{2} \approx\right.$ $100 \%)$.

$\mathrm{SO}_{2}$ is the microvascular tissue oxygen saturation ${ }^{30}\left(\mathrm{SO}_{2}=\right.$ $\mathrm{HbO}_{2} / \mathrm{HbT}$ ). By considering Grubb's relation between changes in $\mathrm{rCBF}$ and $\mathrm{rCBV}^{31}(\beta=0.9)^{21}$ (time invariant characteristic of beta has been validated statistically):

$\mathrm{rCBF}=\frac{\mathrm{CBF}_{i}(t)}{\mathrm{CBF}_{i}\left(t_{0}\right)}=\left[\frac{\mathrm{CBV}(t)}{\operatorname{CBV}\left(t_{0}\right)}\right]^{\beta}=(\mathrm{rCBV})^{\beta}$,

$\mathrm{rCMRO}_{2}=(\mathrm{rCBV})^{\beta} \times \mathrm{rOEF}$.

$\mathrm{CBV}$ was defined as $\mathrm{CBV}=\frac{\left(\mathrm{HbT} \times \mathrm{MW}_{\mathrm{Hb}}\right)}{\mathrm{HGB} \times D_{\mathrm{bt}}}$, where $\mathrm{CBV}$ is expressed in $\mathrm{ml} / 100 \mathrm{~g}$, $\mathrm{HbT}$ in $\mu \mathrm{mol}, \mathrm{MW}_{\mathrm{Hb}}(64,500 \mathrm{~g} / \mathrm{mol})$ is the molecular weight of hemoglobin, $D_{\mathrm{bt}}(1.05 \mathrm{~g} / \mathrm{ml})$ is the brain tissue density, and HGB ( $\mathrm{g} / \mathrm{dl})$ is the blood hemoglobin concentration. The control state at time $t_{0}$ was defined as the mean value of the signal and was considered to be the reference value.

\subsection{Nonlinear Flow-Metabolism Interaction by Transfer Entropy}

TE was used to define the strength of causality and the coupling between $\mathrm{rCBV}-\mathrm{rCBF}$ and $\mathrm{rCBF}-\mathrm{rCMRO}_{2}$. The concept of entropy is related to the degree of uncertainty associated with a signal random variable (i.e., rCBF). In other words, it provides a measure of the average uncertainty in a random variable. The determination of entropy of a random variable $\mathrm{rCBF}$ with a probability mass function $P(\mathrm{rCBF})$ is defined by the following equation:

$\mathrm{H}(\mathrm{rCBF})=\sum_{\mathrm{i}=1}^{N}-P\left(\mathrm{rCBF}_{i}\right) \log \left[P\left(\mathrm{rCBF}_{i}\right)\right]$.

The first step consisted of the evaluation of the entropy $(\mathrm{H})$ corresponding to the uncertainty associated with one of the two variables, rCBV, and rCBF. The analysis was based on timesseries with identical probability variables and a flat distribution of quantized values. The original normal distribution of the two variables (rCBF and $\mathrm{rCBV}$ ) is shown in Fig. 2(a). In order to produce time-series with identical probability variables of $\mathrm{rCBF}$ and $\mathrm{rCBV}$, raw $\mathrm{rCBF}$ and $\mathrm{rCBV}$ data were quantized using 25 th, 50th, 75th, and 100th percentiles, and $\mathrm{rCBF}$ and $\mathrm{rCBV}$ values between the $(0,25$ th $),(25$ th, 50th), (50th, 75th), and (75th, 100th) percentiles, corresponding to $1,2,3,4$, respectively, in Fig. 2(b). The quantized $\mathrm{rCBF}$ and $\mathrm{rCBV}$ values presented the required flat distribution [Fig. 2(c)].

The reduction of the uncertainty of one random variable obtained by the addition of a second variable (i.e., rCBV, where $\mathrm{rCBV}$ is not completely independent of $\mathrm{rCBF}$ ), is defined as mutual information (MI). MI is a measure of the amount of (a)

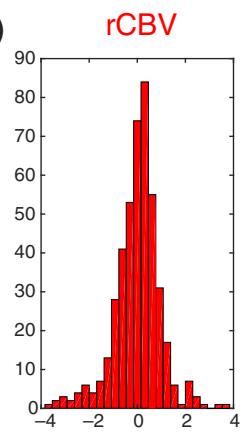

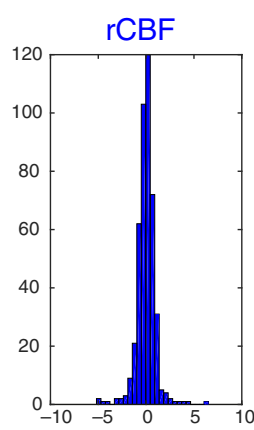

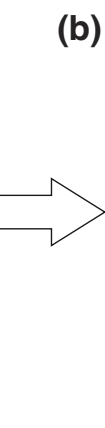

(b)

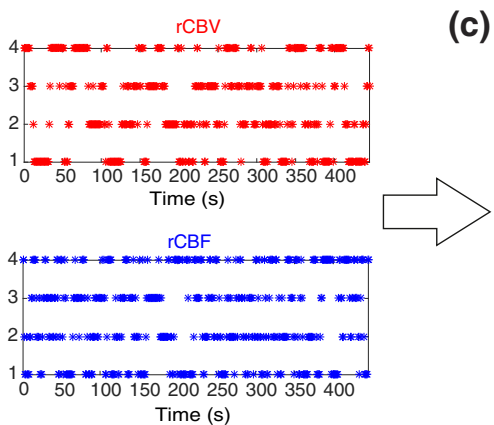

(c)

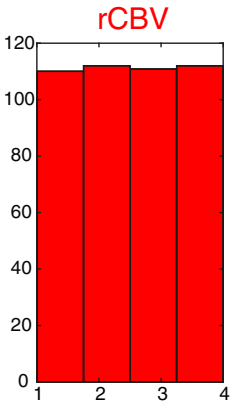

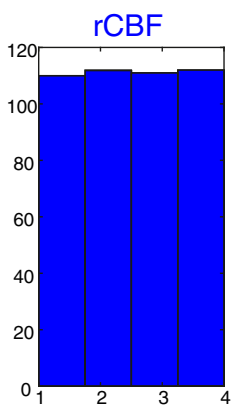

(d)
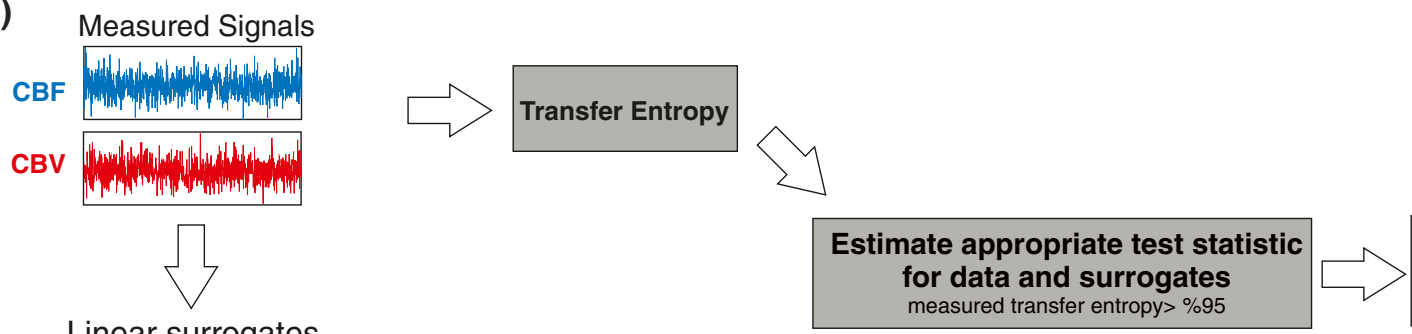

Linear surrogates

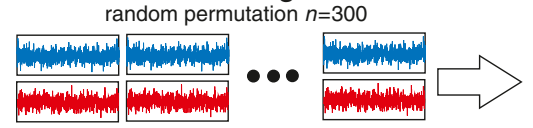

Transfer Entropy

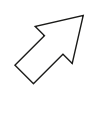

Fig. 2 (a) Distribution histogram of $\mathrm{rCBV}$ and $\mathrm{rCBF}$, (b) time-series of rCBV and rCBF expressed as quantized values to produce time-series with identical probability variables, (c) flat distribution of rCBV and rCBF, and (d) diagram of the surrogate data approach to the rCBF-rCBV coupling hypothesis. 
information that one random variable provides about another random variable, defined by $\mathrm{H}(\mathrm{rCBF}, \mathrm{rCBV})$ corresponding to the entropy of the two variables, $\mathrm{rCBF}$, and $\mathrm{rCBV}$ :

$$
\begin{aligned}
\mathrm{MI}(\mathrm{rCBF}, \mathrm{rCBV})= & H(\mathrm{rCBF})+H(\mathrm{rCBV}) \\
& -H(\mathrm{rCBF}, \mathrm{rCBV}) .
\end{aligned}
$$

The second step consisted of the evaluation of the MI shared by the two variables. To evaluate the interdependency between the two variables, $\mathrm{rCBV}$, and $\mathrm{rCBF}$, the MI was compared to the entropy $(\mathrm{H})$ of each variable. When MI between these two variables is less than entropy $(\mathrm{H})$, it can be concluded that the two variables are dependent.

As MI is symmetrical for the exchange of signals, it captures the information shared by two signals but is unable to distinguish the driving signal. The reduction in the uncertainty of rCBF due to the information provided by $\mathrm{rCBV}$ can also be obtained by introducing a third variable, resulting in conditional mutual information (CMI). The MI between $\mathrm{rCBF}$ and $\mathrm{rCBV}$ conditioned by a third variable corresponds to the part of the information derived from simultaneous analysis of $\mathrm{rCBF}$ and $\mathrm{rCBV}$ that is unrelated to the third variable (i.e., $Z$ ):

$$
\begin{aligned}
\mathrm{CMI}(\mathrm{rCBF}, \mathrm{rCBV} \mid Z)= & H(\mathrm{rCBF}, Z)+H(\mathrm{rCBV}, Z) \\
& -H(\mathrm{rCBF}, \mathrm{rCBV}, Z)-\mathrm{H}(Z) .
\end{aligned}
$$

To obtain an asymmetrical measure, the bivariate version of CMI was used, wherein the third variable is a lagged version of variable $\mathrm{rCBF}$ or $\mathrm{rCBV}$ (delayed MI). It states that a signal $\mathrm{rCBF}$ is caused by signal rCBV when the future of signal $\mathrm{rCBV}$ is more accurately predicted by appending information from the past and present of signal rCBF than by using information from the present and past of signal rCBV alone. ${ }^{18}$ Delayed MI shows a causal dependence related to the information exchanged rather than the information shared (for instance, due to a common drive of both signals by a third external source). ${ }^{32}$ $\mathrm{TE}$ from $\mathrm{rCBF}$ to $\mathrm{rCBV}$ is defined by the following equation, where $t$ is a discrete time-index value:

$$
\begin{aligned}
\mathrm{TE} & (\mathrm{rCBV} \rightarrow \mathrm{rCBF})=\mathrm{CMI}\left(\mathrm{rCBF}_{t}, \mathrm{rCBV}_{t-1} \mid \mathrm{rCBF}_{t-1}\right) \\
= & H\left(\mathrm{rCBF}_{t}, \mathrm{rCBF}_{t-1}\right)+H\left(\mathrm{rCBV}_{t-1}, \mathrm{rCBF}_{t-1}\right) \\
& -H\left(\mathrm{rCBF}_{t}, \mathrm{rCBV}_{t-1}, \mathrm{rCBF}_{t-1}\right)-H\left(\mathrm{rCBF}_{t-1}\right),
\end{aligned}
$$

$$
\begin{aligned}
& \mathrm{TE}(\mathrm{rCBF} \rightarrow \mathrm{rCBV})=\mathrm{CMI}\left(\mathrm{rCBV}_{t}, \mathrm{rCBF}_{t-1} \mid \mathrm{rCBV}_{t-1}\right) \\
& =H\left(\mathrm{rCBV}_{t}, \mathrm{rCBV}_{t-1}\right)+H\left(\mathrm{rCBF}_{t-1}, \mathrm{rCBV}_{t-1}\right) \\
& -H\left(\mathrm{rCBV}_{t}, \mathrm{rCBF}_{t-1}, \mathrm{rCBV}_{t-1}\right)-H\left(\mathrm{rCBV}_{t-1}\right)
\end{aligned}
$$

The information transfer between $\mathrm{rCBV}$ and $\mathrm{rCBF}$ was measured by the time-lagged CMI. By applying time-lagged CMI to the two variables ( $\mathrm{rCBF}$ and $\mathrm{rCBV})$, if $\mathrm{TE}(\mathrm{rCBF} \rightarrow \mathrm{rCBV})$ is less than $\mathrm{TE}(\mathrm{rCBV} \rightarrow \mathrm{rCBF})$, it can be concluded that $\mathrm{rCBF}$ is more dependent on $\mathrm{rCBV}$.

Then, because TE is based on transition probabilities, it can be used to determine the dominant direction in the relationship between two variables. The directionality index (DI) between two variables $\mathrm{rCBF}$ and $\mathrm{rCBV}$ is calculated by

$$
\mathrm{DI}(\%)=\frac{\mathrm{TE}(\mathrm{rCBV} \rightarrow \mathrm{rCBF})-\mathrm{TE}(\mathrm{rCBF} \rightarrow \mathrm{rCBV})}{\mathrm{TE}(\mathrm{rCBV} \rightarrow \mathrm{rCBF})+\mathrm{TE}(\mathrm{rCBF} \rightarrow \mathrm{rCBV})} \times 100
$$

When DI $>0$, it was concluded that the $\mathrm{CCBV}$ was predominant over rCBF. Conversely, when $\mathrm{DI}<0$, rCBF controlled $\mathrm{rCBV}$ and, $\mathrm{DI}=0$ indicates balanced bilateral interactions between the two variables. The statistical significance of TE and MI measurements was evaluated by using a surrogate method by measuring the dependency of two time-series ( $\mathrm{rCBF}$ and $\mathrm{rCBV}$ ) with one of the signals randomly shuffled and reorganized and with each sample replaced in a random position in the series. The limit of statistical confidence corresponding to the 95th percentile was found by repeating a different permutation on one of the signals 300 times.

The third step consisted of the evaluation of the direction of the relationships between $\mathrm{rCBF}$ and $\mathrm{rCBV}$, which can be determined by the DI on both measured and surrogate data. The confidence intervals can be used to calculate statistical power in order to conclude that a surrogate explains at least a certain proportion of the correct direction. If the test statistic from the data is higher than the 95th percentile of the surrogate, it demonstrates the reliability of the estimation procedure [Fig. 2(d)]. All steps were identical for investigation of the relationship between $\mathrm{rCBF}$ and $\mathrm{rCMRO}_{2}$.

\section{Results}

\subsection{Linear Interaction Between $r C B F-r C B V$ and $r C B F-r C M R O_{2}$}

Changes in $\mathrm{rCBV}$ were plotted as a function of $\mathrm{rCBF}$ for 10 subjects [Fig. 3(a)], resulting in a fluctuating correlation between $\mathrm{rCBV}$ and $\mathrm{rCBF}$ with a tendency toward a positive correlation in 6/10 preterms and a negative correlation in the remaining four preterms with an average slope of $0.02 \pm 0.12$.

\subsection{Computation of Transfer Entropy}

The entropy $(\mathrm{H})$ of $\mathrm{rCBF}$ and $\mathrm{rCBV}$ for each subject and each parameter was equal to 2 . For each subject, the MI of $\mathrm{rCBF}$ and $\mathrm{rCBV}$ was less than the entropy $(\mathrm{H})$ of $\mathrm{rCBV}$ and $\mathrm{rCBF}$ $\left[\mathrm{MI}_{(\mathrm{rCBF}, \mathrm{rCBV})}<\mathrm{H}_{(\mathrm{rCBV})}\right.$ and $\left.\mathrm{MI}_{(\mathrm{rCBF}, \mathrm{rCBV})}<\mathrm{H}_{(\mathrm{rCBF})}\right]$ [Fig. 3(b)]. By considering $\mathrm{rCMRO}_{2}$ as a product of the measured $\mathrm{HbT}$ and $\mathrm{HbO}_{2}$, the same analysis was performed to test the relationship between $\mathrm{rCBF}$ and $\mathrm{rCMRO}_{2}$ (Fig. 4). Selected parts of $\mathrm{rCMRO}_{2}$ and $\mathrm{rCBF}$ for subjects \#4 and \#10, illustrating the evaluation of TE from $\mathrm{rCMRO}_{2}$ to $\mathrm{rCBF}$ as indicated by circles on signals in the dark gray box, suggest that the source signal $\left(\mathrm{rCMRO}_{2}\right)$ drives the target signal (rCBF) [Fig. 4(a)]. The entropy $(\mathrm{H})$ of $\mathrm{rCBF}$ and $\mathrm{rCMRO}_{2}$ for each subject and each parameter was equal to 2. For each subject, $\mathrm{MI}$ of $\mathrm{rCBF}$ and $\mathrm{rCMRO}_{2}$ was less than the entropy $(\mathrm{H})$ of $\mathrm{rCMRO}_{2}$ and $\mathrm{rCBF}$. The average value of $\mathrm{MI}(\mathrm{MI}=0.0343)$ was less than the entropy $(\mathrm{H}=2)$ [Fig. 4(b)]. These results indicate that $\mathrm{rCBF}$ and rCBV (also, rCBF and $\mathrm{rCMRO}_{2}$ ) can be considered to be dependent variables at the resting state in the preterm brain.

\subsection{Causal Relationship Between rCBF-rCBV and $r C B F-r C M R O_{2}$}

TE was used to identify a causal relationship between $\mathrm{rCBF}$ and $\mathrm{rCBV}$, as it detects the relationship between the past of one 
(a)
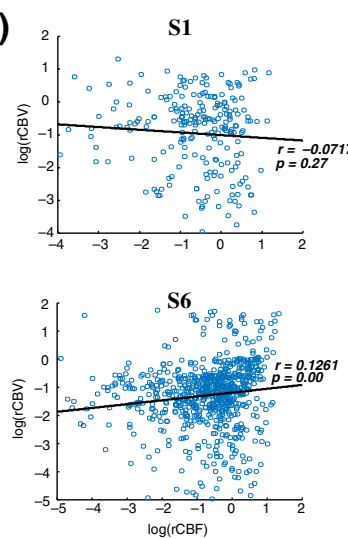
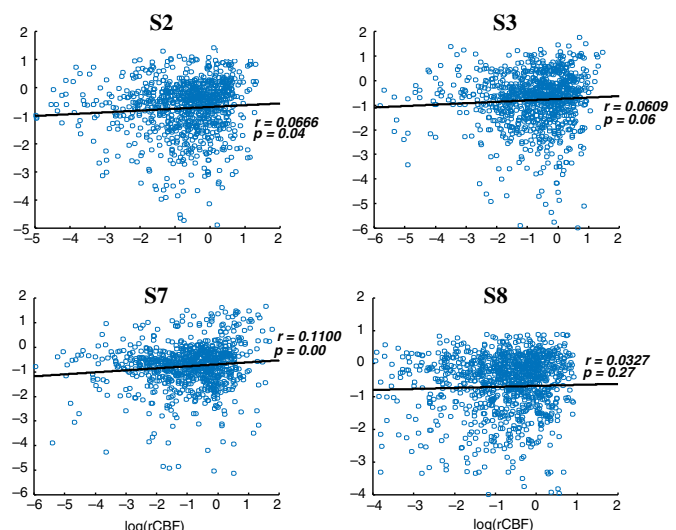
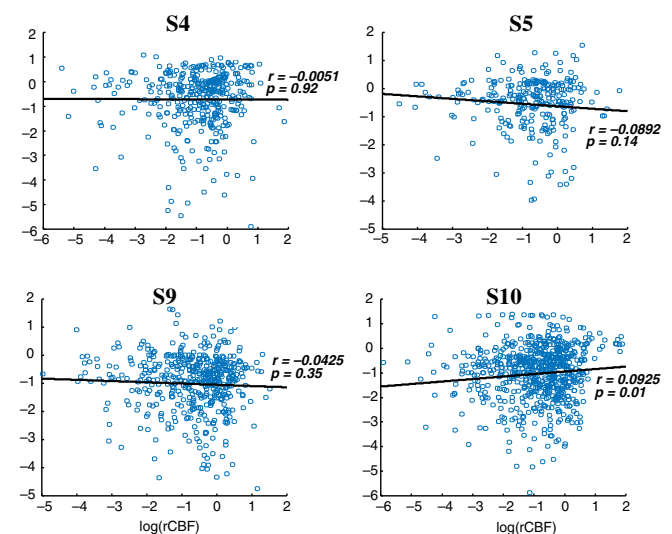

(b)

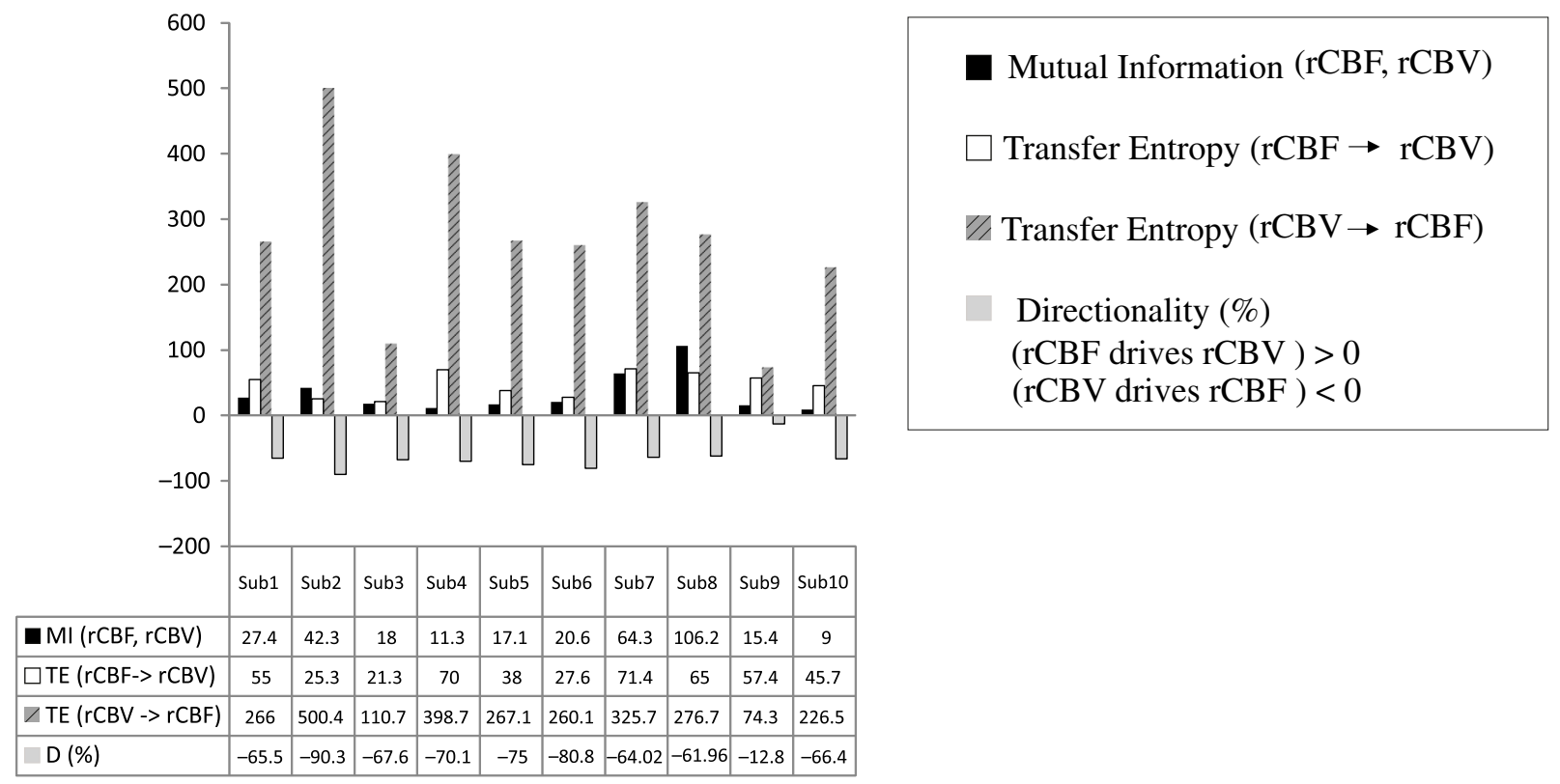

Fig. 3 (a) Correlation between $\log (\mathrm{rCBV}) \_\log (\mathrm{rCBF})$ and (b) amount of information shared between rCBF and $\mathrm{rCBV}$ measured by MI, TE indicates the amount of information exchanged from rCBF to rCBV and vice versa and DI. ("all values are multiplied by 103).

signal $(\mathrm{rCBV})$ and the present of another signal $\left(\mathrm{rCBF}_{t+}\right)$. For each subject, $\mathrm{TE}_{(\mathrm{rCBF} \rightarrow \mathrm{rCBV})}$ was less than $\mathrm{TE}_{(\mathrm{rCBV} \rightarrow \mathrm{rCBF})}$ and the average value of $\mathrm{TE}_{(\mathrm{rCBF} \rightarrow \mathrm{rCBV})}(0.0476)$ was less than the average value of $\mathrm{TE}_{(\mathrm{rCBV} \rightarrow \mathrm{rCBF})}(0.2702)$ [Fig. 3(b)]. These results demonstrate that $\mathrm{rCBF}_{t+}$ appears to be more dependent on rCBV than $\mathrm{rCBV}_{t+}$ on rCBF, suggesting that $\mathrm{rCBV}$ drives $\mathrm{rCBF}$ at the resting state in the preterm brain.

This relationship can be summarized by the DI between rCBF and rCBV [Fig. 3(b)]. The negative values of the DI $(\mathrm{DI}<0)$ suggest that $\mathrm{rCBV}$ was predominant over rCBF. Statistical analysis with a limit of statistical confidence corresponding to the 95th percentile of the 300 trials was performed according to the surrogate method. As the DI measured in each of the 10 subjects was higher than the 95th percentile, statistical analysis robustly detected the correct direction of $\mathrm{rCBV}$ on $\mathrm{rCBF}$. By applying the same analysis to the relationship between the $\mathrm{rCBF}$ and $\mathrm{rCMRO}_{2}$, the negative values of DI $<0$ suggest that estimated $\mathrm{rCMRO}_{2}$ would be predominant over measured $\mathrm{rCBF}$ [Figs. 4(c) and 4(d)].

\subsection{Directionality from $r C B V$ to $r C B F$ with $G A$ at the Time of the Test, Vascular Resistance Index, Apgar Score at $1 \mathrm{~min}$ and at $5 \mathrm{~min}$, Bilateral Intraventricular Hemorrhage-III in Preterm Neonates}

Relationship of directionality from $\mathrm{rCBV}$ to $\mathrm{rCBF}$ with GA at the time of the test, vascular resistance index, Apgar score at $1 \mathrm{~min}$ and at $5 \mathrm{~min}$, bilateral intraventricular hemorrhage (IVH-III) in preterm neonates was investigated. Figure 5 shows the directionality between $\mathrm{rCBV}$ and $\mathrm{rCBF}$ as a function of GA at the time of the test $\left(R^{2}=0.003, P\right.$-value $\left.=0.78\right)[$ Fig. 5(a)], a function of vascular resistance index $\left(R^{2}=0.072, P\right.$-value $=$ $0.26)$ [Fig. 5(b)], a function of Apgar score (1 min) $\left(R^{2}=0.254\right.$, $P$-value $=0.100)$ and Apgar score $(5 \mathrm{~min})\left(R^{2}=0.046\right.$, $P$-value $=0.518)[$ Fig. 5(c)], The results do not demonstrate any significant relationship between maturational stage, vascular resistance index, Apgar score, and developmental dynamics of the relationship between $\mathrm{rCBF}$ and $\mathrm{rCBV}$. More subjects 
(a)
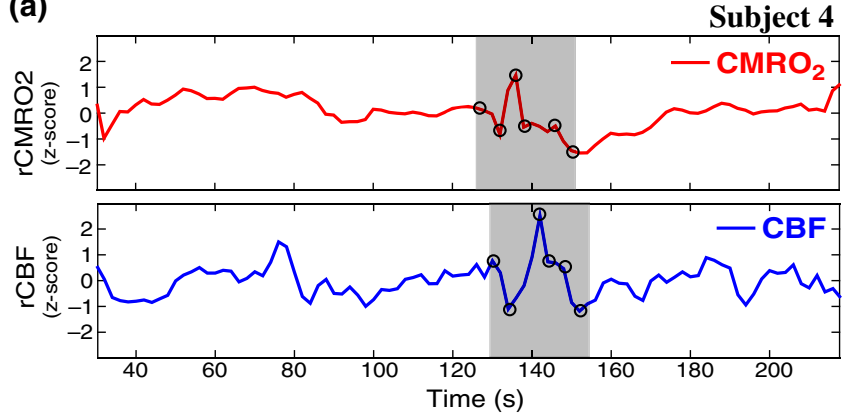
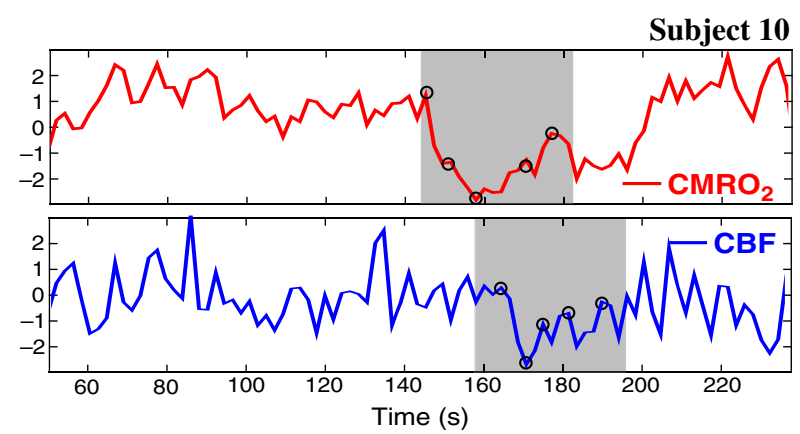
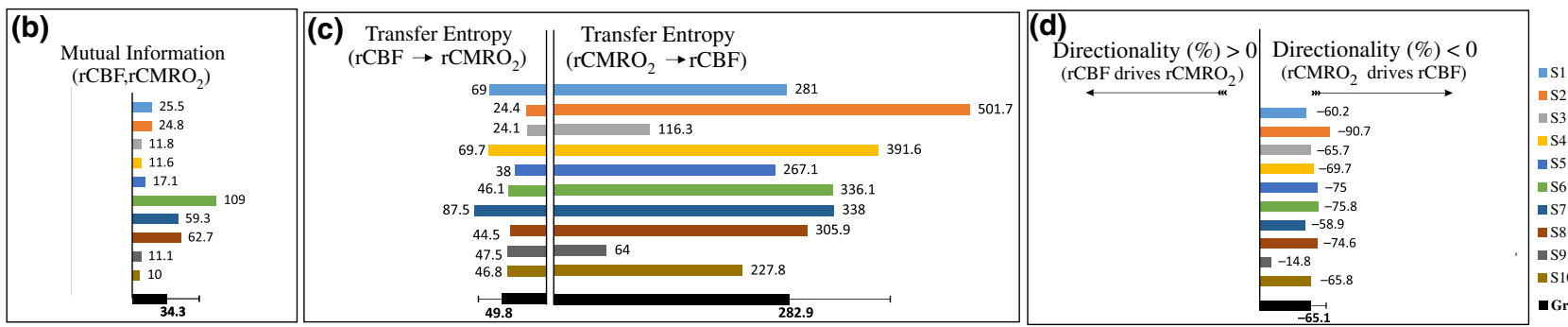

Fig. 4 (a) A selected part of $\mathrm{rCMRO}_{2}$ and $\mathrm{rCBF}$ (subjects \#4, \#10), illustrating evaluation of TE from $\mathrm{rCMRO}_{2}$ to $\mathrm{rCBF}$, (b) Ml shared between rCBF_rCMRO rCBF to $\mathrm{rCMRO}_{2}$ and vice versa, (d) DI. (*all values are multiplied by 103).

could be recruited in future studies in order to investigate the impact of GA, vascular resistance index, Apgar score, bilateral IVH-III on TE.

\subsection{Relationship Between $\mathrm{rCMRO}_{2}$ and Mean Arterial Blood Pressure at the Resting State in Preterm Neonatal Brain}

Figure 6 shows the relationships between $\mathrm{rCMRO}_{2}$ and mean arterial blood pressure (MABP). The nonzero MI between $\mathrm{rCMRO}_{2}$ and MABP demonstrates that the two variables are partially dependent on each other, suggesting that $\mathrm{rCMRO}_{2}$ might also be partly dependent on other systemic variables.

On the other hand, the grand averages of 10 subjects for the linear correlation between $\mathrm{rCMRO}_{2}$ and MABP, and $\mathrm{rCMRO}_{2}$ and heart rate $(\mathrm{HR})$ were not statistically significant $\left(Y_{\mathrm{rCMRO} 2}=\right.$ -0.0059 . $X_{\mathrm{MABP}}+0.0005, \quad P=0.4$ and $Y_{\mathrm{HR}}=-0.0056$. $X_{\mathrm{rCMRO} 2}+0.00056, P=0.6$, respectively).

\subsection{Impact of Possible Time Lag Variability}

Analysis of directionality is often based on synchrony assumptions of the two signals, suggesting that time lag variability would have an impact on the conclusions. It is, therefore, important to assess this time lag effect by means of sensitivity analyses. We considered different time lags between 0.8 to $2.4 \mathrm{~s}$ [DCS sampling period $(2.5 \mathrm{~s})$ is the maximum possible time lag]. Figure 7 shows that time lag changes had a negligible impact on the DI. The consistency between the results of primary analysis and the results of maximum possible time lag analysis, therefore, support the conclusions and the credibility of the results.

\subsection{Effect of Different Beta Values on Transfer Entropy}

We used a constant value for beta in Grubb's equation $(\beta=$ $0.9){ }^{21}$ The effect of different constant $\beta$ values $(0.1,0.2,0.3$,
$0.4,0.75,1,2)$ on TE between $\mathrm{rCBF}$ and $\mathrm{rCMRO}_{2}$ was investigated (Fig. 8). Regardless of the $\beta$ value considered, the directionality of $\mathrm{rCMRO}_{2}$ was predominant over $\mathrm{rCBF}$.

\section{Discussion}

This study demonstrates that, in very preterm newborns ( $<32 \mathrm{wGA}$ ), rCBV is predominant over $\mathrm{rCBF}$ and that neurovascular interactions appear to be sufficiently efficient for $\mathrm{rCMRO}_{2}$ to be already able to drive rCBF at rest.

While our previous data ${ }^{13,14}$ supported the existence of neurovascular coupling in response to neuronal activations by auditory stimuli in very preterm infants, little is known about the interactions between $\mathrm{rCBF}$ and $\mathrm{rCBV}$ (and between $\mathrm{rCBF}$ and $\mathrm{rCMRO}_{2}$ ) in preterms at rest, ${ }^{15}$ in whom the cardiovascular and autonomic nervous systems remain largely immature. The linear relationship between $\mathrm{rCBF}$ and $\mathrm{rCBV}\left(\mathrm{rCBF}\right.$ and $\mathrm{rCMRO}_{2}$ ) has been extensively studied at rest in adult humans ${ }^{5}$ (during sleep ${ }^{33}$ and under general anesthesia ${ }^{34}$ ) and in animals, ${ }^{35,36}$ showing that $\mathrm{CBF}$ and $\mathrm{CBV}$ (as well as $\mathrm{CBF}$ and $\left.\mathrm{CMRO}_{2}\right)^{37}$ are tightly coupled under normal conditions. In the present study, the linear correlation between $\mathrm{rCBF}$ and $\mathrm{rCBV}$ was fluctuating with a tendency to be either positive $(n=6)$ or negative $(n=4)$ [Fig. 3(a)], which is consistent with the results in preterm infants reporting rather stable $\mathrm{rCBV}$ whatever the changes in $\mathrm{rCBF}^{21} \mathrm{In}$ comparison to the mature adult brain, presenting high coupling between CBF and CBV, a weaker correlation between these two variables was observed in the developing neonatal brain.

Most studies have explored the linear relationships between $\mathrm{rCBF}$ and $\mathrm{rCBV}^{21}\left(\mathrm{rCBF}\right.$ and $\left.\mathrm{rCMRO}_{2}{ }^{15}\right)$. To the best of our knowledge, this is the first study to evaluate the nonlinear relationships between $\mathrm{rCBF}$ and $\mathrm{rCBV}$ in preterm infants, demonstrating the intensity and asymmetry of the interactions between these two autonomic variables, i.e., $\mathrm{rCBF}$ and $\mathrm{rCBV}$, using $\mathrm{TE}$ analysis derived from information theory. ${ }^{16}$ To ensure the independency of the recorded parameters, $\mathrm{rCBF}$ and $\mathrm{rCBV}$ were 
(a)

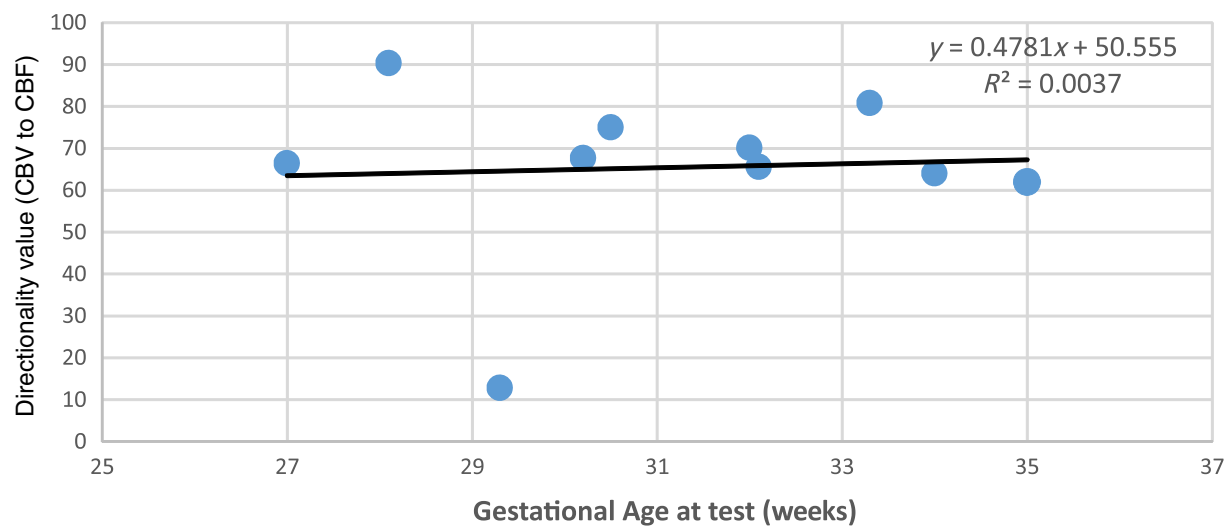

(b)

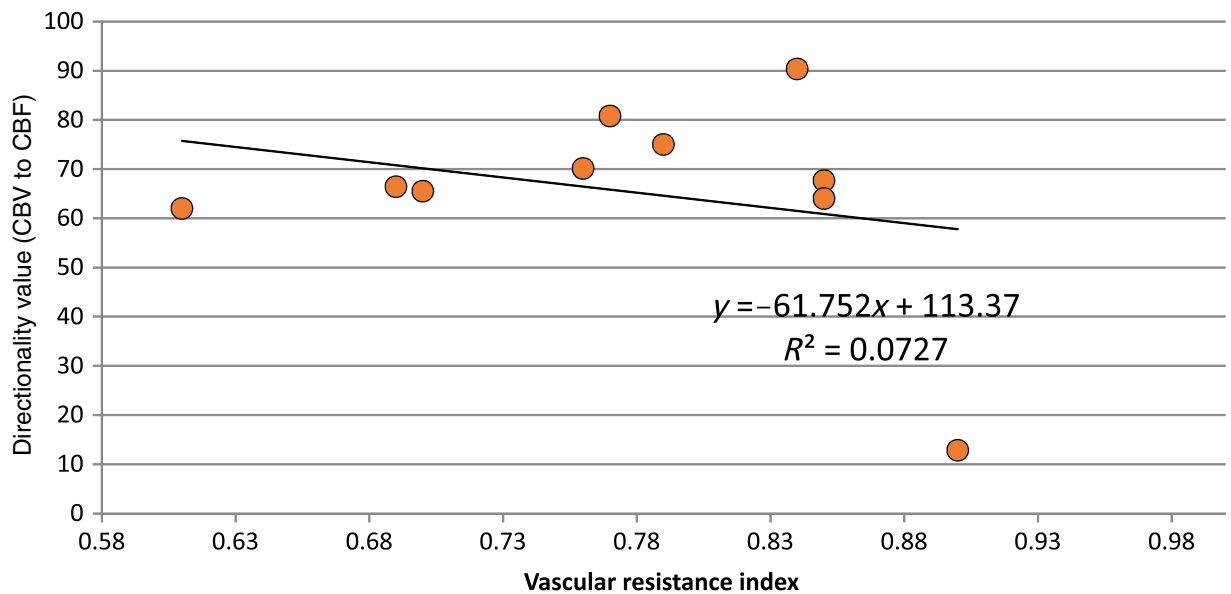

(c)

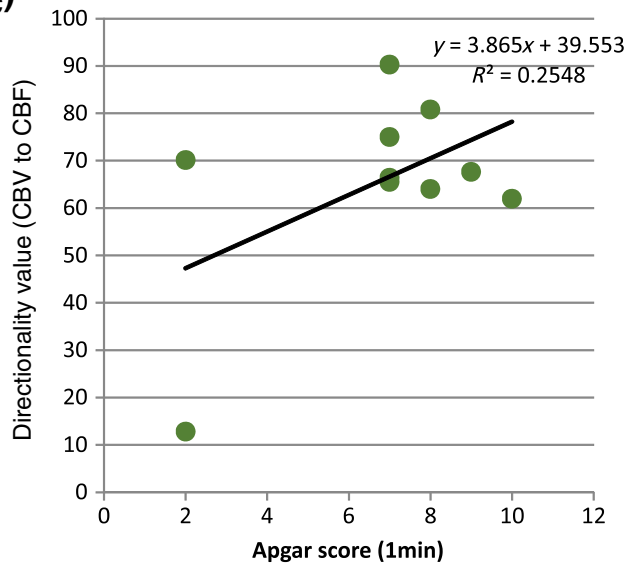

(d)

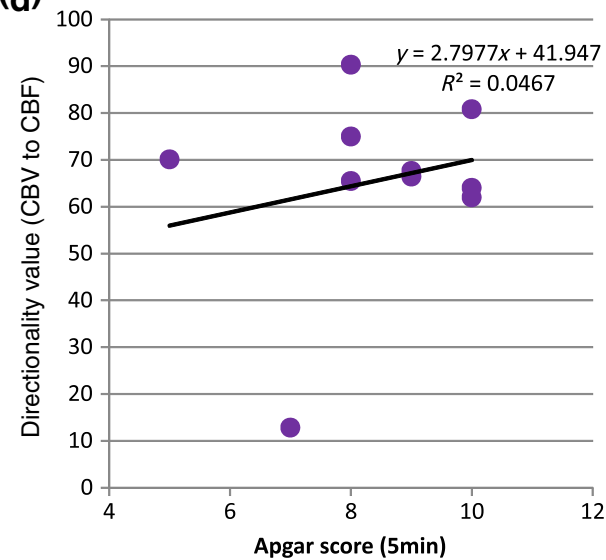

Fig. 5 Directionality\% (rCBV to rCBF) as a function of (a) GA at the time of the test (weeks), (b) vascular resistance index, (c) Apgar score at $1 \mathrm{~min}$, and (d) Apgar score at $5 \mathrm{~min} . R^{2}$ and the linear regression equation are indicated in the upper right corner of the graph.

simultaneously recorded by two separate devices using two different approaches, DCS and NIRS, respectively.

In preterms, the negative $\mathrm{DI}(\mathrm{DI}<0)$ between $\mathrm{rCBV}$ and rCBF suggests that $\mathrm{rCBV}$ has a more predominant driving influence on $\mathrm{rCBF}$ (versus $\mathrm{rCBF}$ to $\mathrm{rCBV}$ ) at the resting state. We tested to what degree the maximum time lag between the two separate devices would affect the results, despite the fact that the acquisition devices were synchronized by an external event trigger. The maximum possible lag changes (Fig. 7) and the effect of different constant values of $\beta$ (Fig. 8) had a negligible impact on the DI. Our results at resting state are in agreement with those reported by Roche-Labarbe et al., ${ }^{6}$ although their study was conducted under different conditions, with large in-flow modeled related to task-evoked conditions, such as somatosensory stimulation. ${ }^{6}$ During the first few seconds of stimulation, rCBV increased progressively, while changes in $\mathrm{rCBF}$ started to increase abruptly after only a few seconds, ${ }^{6}$ suggesting a lag between changes in $\mathrm{rCBV}$ and $\mathrm{rCBF}$.

Notwithstanding the methodological limitations [(i) small differences in tissue volume sampled, (ii) optimization of the distances between emitters and detectors of the NIRS and DCS probes to minimize light interferences, (iii) higher integration 


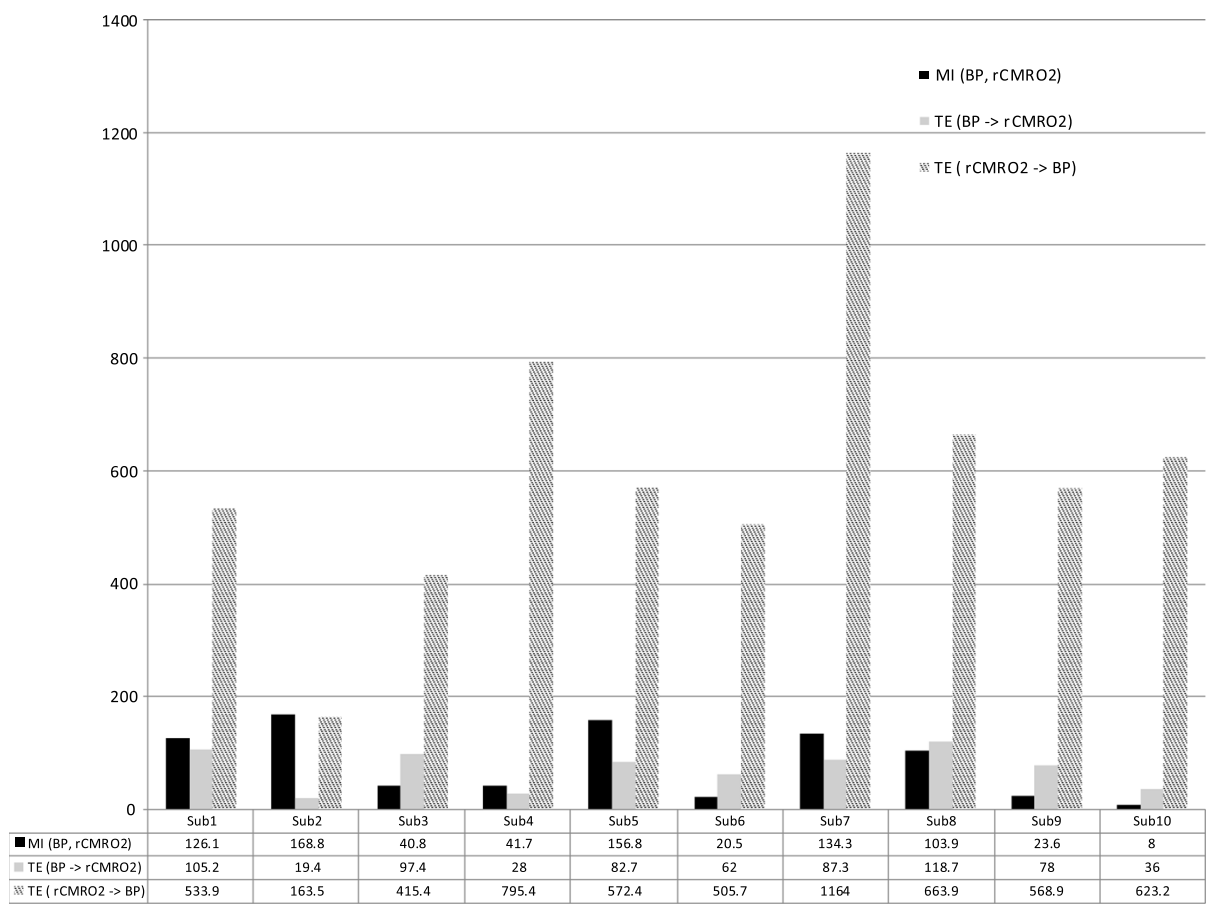

Fig. 6 Amount of information shared between $\mathrm{rCMRO}_{2}$ and MABP measured by $\mathrm{MI}$, TE indicates the amount of information exchanged from $\mathrm{rCMRO}_{2}$ to MABP and vice versa.

time for DCS than for NIRS to achieve a balance between signal quality and temporal resolution] and the physiological complexity (arteriole resistance, arterial/venous/capillary compartment), the use of information entropy has the advantage of combining the probabilities for multiple outcomes to one meaningful measure, i.e., the directionality from $\mathrm{rCBV}$ to $\mathrm{rCBF}$, and it does not assume a specific statistical distribution or an estimate of a mean.

TE implies to quantify the causal relationship between the variables (i.e., rCBV and $\mathrm{rCBF}$ ). The causality does not necessarily imply that two variables have a time lag, they also could have taken place simultaneously. Increased volume followed by increased flow with a slight delay (i.e., time lag between the rCBV and $\mathrm{rCBF}$ ), directs us to explore for a suitable physiological underlying mechanism. Although the reports of relative CBV and CBF dynamics have been controversial, ${ }^{4,38,39}$ our finding (rCBV followed by rCBF changes) supports the assumption of a process of capillary filling (increase in $\mathrm{rCBV}$ ) ${ }^{38}$ followed by a delayed neurovascular regulation of $\mathrm{rCBF}$ in the capillary bed. Functional recruitment of capillaries is the changeover of low blood flow to high blood flow capillaries. ${ }^{40}$ An initial phase of activation can be expected when local capillary blood volume increases, but at a time when arterioles have not yet dilated and the blood flow has not yet increased. ${ }^{38}$ This type of lagged relationship between blood volume and blood flow has been described to be valid if the outflow from the capillary compartment in the activated regions is briefly lower than the inflow to this capillary compartment. ${ }^{38}$ The capacitance of the capillaries was to raise and their resistance was to reduce, following neuronal activation (i.e., the capillary bed might play as a "sink" for red blood cells). ${ }^{38}$ This in turn allows the outflow from the compartment to decrease before the occurrence of upstream arteriolar dilatation that would provoke an increased inflow. Thereafter, when the arteriolar part has dilated, the increased inflow causes a flow increase in the entire capillary compartment, oxyhemoglobin increases, and deoxyhemoglobin decreases. ${ }^{38}$

Leung et al. ${ }^{24}$ suggested that Grubb's relation cannot be used to estimate $\mathrm{CMRO}_{2}$ because the variances in $\log \left(\mathrm{CBF} / \mathrm{CBF}_{0}\right)$ and $\log \left(\mathrm{CBV} / \mathrm{CBV}_{0}\right)$ measurements would be different, but, in contrast, Boas and Payne noted that: "both of these calculations assume that the dependent variable is functionally dependent on the independent variable and that the variance in the linear regression is exclusively derived from the variance in the dependent variable". rCBF can, therefore, be estimated from $\mathrm{rCBV}$, allowing $\mathrm{rCMRO}_{2}$ to be estimated when only rCBV measurements are available. ${ }^{23}$

By considering the neurovascular coupling cascade (multiple signaling pathways encompassing perivascular astrocytes, vasoactive chemical agents, and direct neuronal connections) $)^{41,42}$ and estimation of $\mathrm{rCMRO}_{2}$ index by $\mathrm{rCBV}^{23}$ the linear correlation between $\mathrm{rCBF}$ and $\mathrm{rCMRO}_{2}$ was also fluctuating with a tendency to be either positive $(n=6)$ or negative $(n=4)$. This fluctuation in the linear correlation between $\mathrm{rCBF}$ and $\mathrm{rCMRO}_{2}$ has already been described in preterm infants, with no relationship observed in healthy preterms, while a strong relationship was observed after dopamine treatment, ${ }^{15}$ suggesting that the underlying mechanisms of the interactions between $\mathrm{rCBF}$ and $\mathrm{rCMRO}_{2}$ in preterms are fairly complex, immature, and have yet to be determined. ${ }^{43}$ The direction of the nonlinear relationship between $\mathrm{rCBF}$ and $\mathrm{rCMRO}_{2}$ is an accepted hypothesis in adults ${ }^{1}$ and supports the idea that $\mathrm{rCBF}$ could be controlled by oxygen demand. ${ }^{44}$

Nonlinear analysis can be used to detect a wider range of interactions between variables compared to conventional analysis, such as linear correlation. Analysis of the nonlinear relationship between $\mathrm{rCBF}$ and $\mathrm{rCMRO}_{2}$, and the negative values of DI suggest that $\mathrm{rCMRO}_{2}$ is significantly predominant over $\mathrm{rCBF}$ in the resting state in the preterm healthy brain. As $\mathrm{rCMRO}_{2}$ depends on the degree of brain activity at the resting state, ${ }^{45}$ 

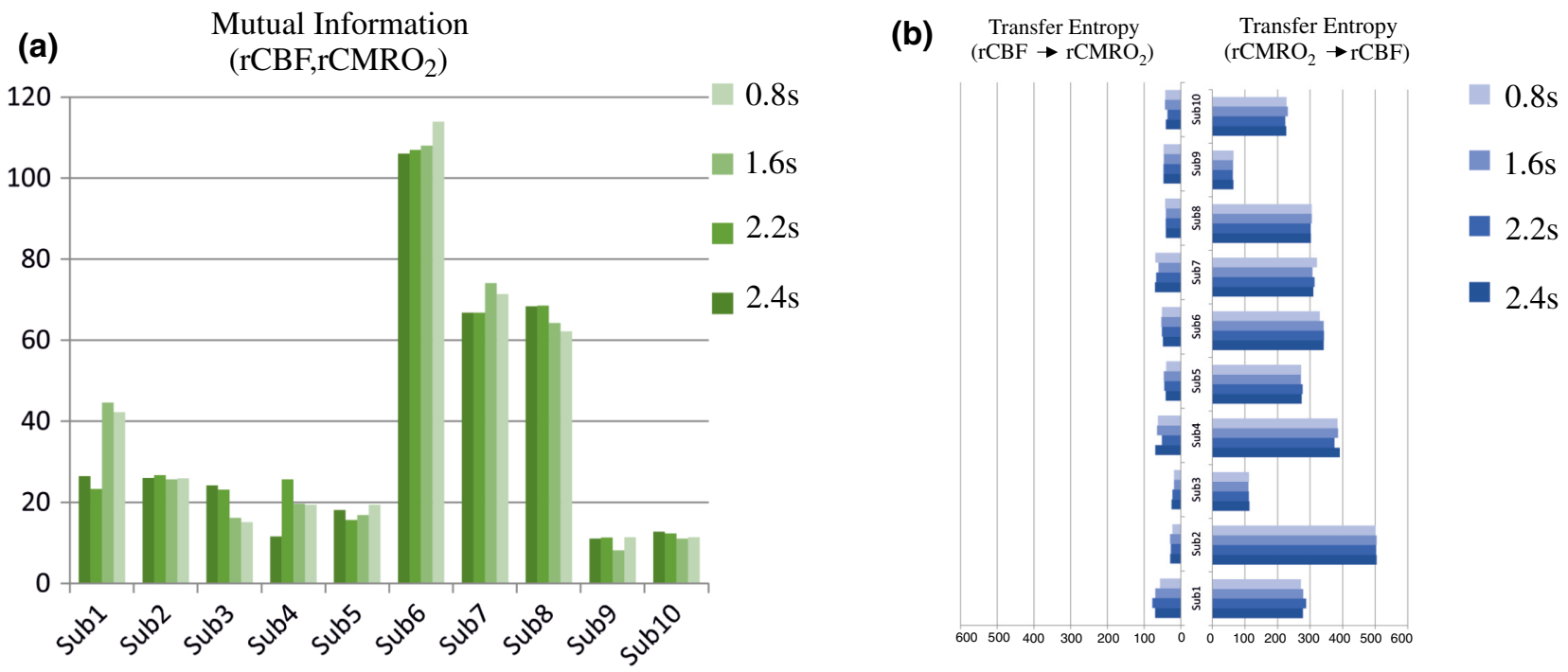

(c)

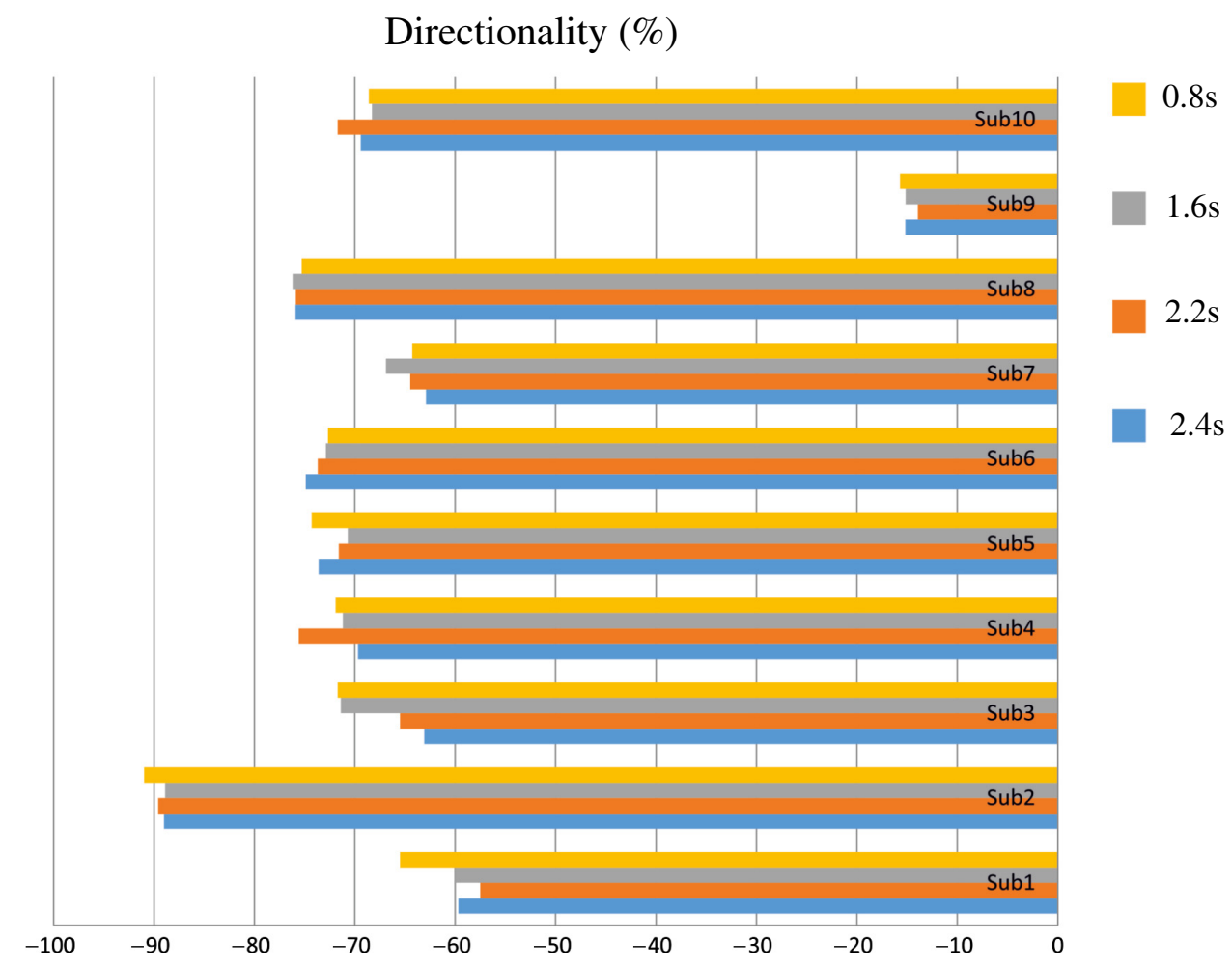

Fig. 7 Impact of time-lagged $\mathrm{rCBF}$ on $\mathrm{rCMRO}_{2}$ with different time lags $(0.8 \mathrm{~s}, 1.6 \mathrm{~s}, 2.2 \mathrm{~s}, 2.4 \mathrm{~s})$ : (a) amount of information shared between $\mathrm{rCBF}$ and $\mathrm{rCMRO}_{2}$ measured by $\mathrm{Ml}$, (b) TE indicates the amount of information exchanged from rCBF to $\mathrm{rCMRO}_{2}$ and vice versa with different time lags, (c) $\mathrm{DI}$ indicates the dominant direction of the transfer, the negative sign indicates the dominance of $\mathrm{rCMRO}_{2}$ over $\mathrm{rCBF}$ and vice versa.

rCBF variations may be partly driven by brain activity at rest. This hypothesis is now being tested in the laboratory by combining EEG, NIRS, and DCS in preterms.

The relationship between $\mathrm{rCMRO}_{2}$ and $\mathrm{MABP}$ was also assessed. The nonzero MI between $\mathrm{rCMRO}_{2}$ and $\mathrm{MABP}$ implies that, although $\mathrm{rCMRO}_{2}$ might be affected by changes in systemic variables, some of the variations of $\mathrm{rCMRO}_{2}$ depend on other variables, such as $\mathrm{rCBF}$. This study also demonstrates a possible relationship between $\mathrm{rCBF}$ and $\mathrm{rCMRO}_{2}$ with a directionality from estimated $\mathrm{rCMRO}_{2}$ to measured $\mathrm{rCBF}$.
The already functional directionality between $\mathrm{rCBF}$ and rCBV or between $\mathrm{rCBF}$ and $\mathrm{rCMRO}_{2}$ suggests that the intimate cellular mechanisms observed in adults, such as the participation of astrocytes and the various signals arising from activated neuronal assemblies and transmitted to perivascular glial endfeet, might be already functional in preterms from 28 wGA, resulting in changes in arterial tone. ${ }^{46}$

This type of analysis could be applied in clinical practice to investigate whether this relationship between $\mathrm{rCBF}$ and $\mathrm{rCBV}$ ( $\mathrm{rCBF}$ and $\mathrm{rCMRO}_{2}$ ) persists in patients at risk of neuronal 


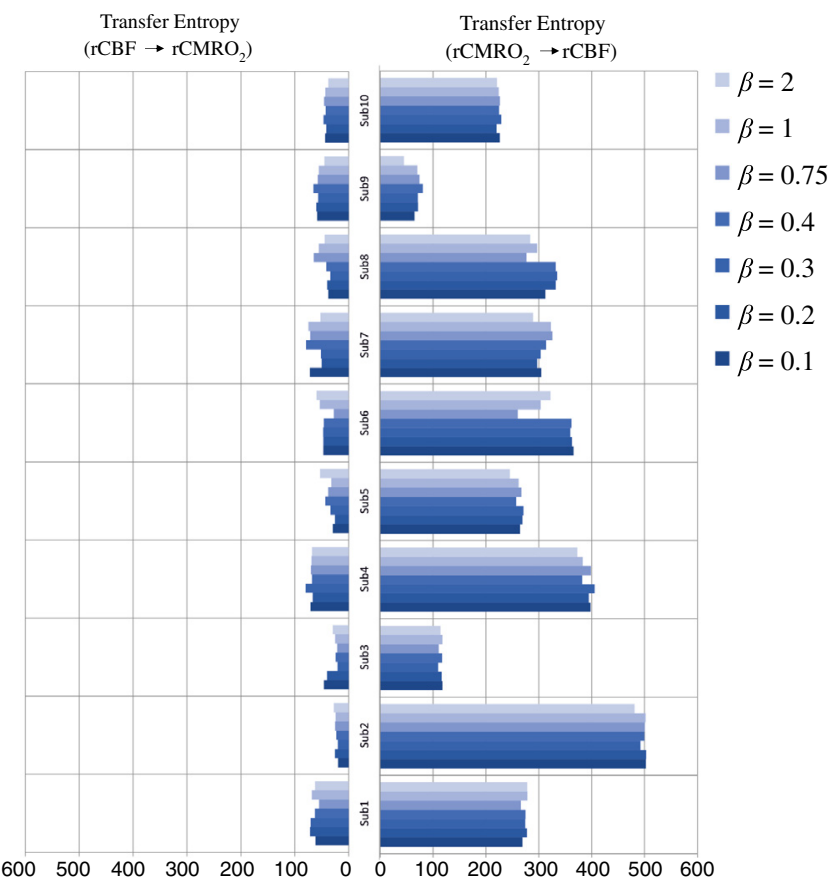

Fig. $8 \mathrm{TE}$ indicates the amount of information exchanged from $\mathrm{rCBF}$ to $\mathrm{rCMRO}_{2}$ and vice versa (10 subjects with seven different values of $\beta$ ).

or vascular brain injury (IVH, hydrocephalus, etc.). The results of this study demonstrate the lowest directionality value $\left(\mathrm{rCMRO}_{2}\right.$ to $\left.\mathrm{rCBF}\right)$ for neonate \#9 with bilateral IVH-III and hydrocephalus. Although a greater number of subjects must be included in future studies, this result is in agreement with those we reported in Mahmoudzadeh et al., ${ }^{47}$ showing the absence of hemodynamic responses induced by phoneme stimuli in IVH III-IV preterms. The results also demonstrate the highest directionality value (rCBV to $\mathrm{rCBF})$ and $\left(\mathrm{rCMRO}_{2}\right.$ to $\left.\mathrm{rCBF}\right)$ in neonate \#2, who was one of the two patients of our study with an abnormal EEG (positive rolandic spikes). Further studies are also required to assess the developmental dynamics of the relationship between $\mathrm{rCBF}$ and $\mathrm{rCBV}\left(\mathrm{rCBF}\right.$ and $\left.\mathrm{rCMRO}_{2}\right)$ at different postnatal ages. The various treatments administered to preterm infants in this study may have influenced the relationship between $\mathrm{rCBF}$ and $\mathrm{rCBV}\left(\mathrm{rCBF}\right.$ and $\left.\mathrm{rCMRO}_{2}\right)$. For example, opioids (morphine) may have decreased $\mathrm{CMRO}_{2}{ }^{48}$ Moreover, it is widely accepted that neurovascular modulations are highly dependent on sedative treatment including direct cerebral vasodilation and significantly reduced cerebral metabolic demand, which would reduce $\mathrm{rCBF}$ in response to neuronal activation during anesthesia. ${ }^{49}$ Strict coupling between $\mathrm{rCBF}$ and $\mathrm{rCMRO}_{2}$ cannot be expected under such conditions. Nevertheless, the directionality from $\mathrm{rCBF}$ to $\mathrm{rCBV}\left(\mathrm{rCBF}\right.$ to $\left.\mathrm{rCMRO}_{2}\right)$ was preserved even in lightly sedated preterms.

\section{Conclusions}

This study focused on the nonlinear relationship between $\mathrm{rCBF}$ and $\mathrm{rCBV}\left(\mathrm{rCBF}\right.$ and $\mathrm{rCMRO}_{2}$ ) in preterm infants recorded before $32 \mathrm{wGA}$. The mechanisms by which $\mathrm{rCBV}$ drives $\mathrm{rCBF}$ $\left(\mathrm{rCMRO}_{2}\right.$ drives $\left.\mathrm{rCBF}\right)$ are already functional at this early age of development regardless of whether or not these two variables are strictly correlated. As the directionality was observed in all preterm infants regardless of the type of anesthesia, it would be interesting to test the application of this technique in routine clinical practice as a potential index of neurovascular coupling in a larger population of preterms at risk of neuronal or vascular brain injury.

\section{Disclosures}

The authors declared no potential conflicts of interest with respect to the research, authorship, and/or publication of this article.

\section{References}

1. C. S. Roy and C. S. Sherrington, "On the regulation of the blood-supply of the brain," J. Physiol. 11(1-2), 85-158 (1890).

2. C. S. Kleinman and I. Seri, Hemodynamics and Cardiology: Neonatology Questions and Controversies, pp. 19103-2899, Elsevier Health Sciences, Philadelphia, Pennsylvania (2012).

3. R. L. Grubb et al., "The effects of changes $\mathrm{PaCO}_{2}$ in cerebral blood volume, blood flow, and vascular mean transit time," Stroke 5(5), 630-639 (1974)

4. M. Jones et al., "Concurrent optical imaging spectroscopy and laserDoppler flowmetry: the relationship between blood flow, oxygenation, and volume in rodent barrel cortex," Neuroimage 13(6 Pt 1), 1002-1015 (2001).

5. H. Ito et al., "Changes in human cerebral blood flow and cerebral blood volume during hypercapnia and hypocapnia measured by positron emission tomography," J. Cereb. Blood Flow Metab. 23(6), 665-670 (2003).

6. N. Roche-Labarbe et al., "Somatosensory evoked changes in cerebral oxygen consumption measured non-invasively in premature neonates," Neuroimage 85(Pt 1), 279-286 (2014).

7. R. B. Buxton, E. C. Wong, and L. R. Frank, "Dynamics of blood flow and oxygenation changes during brain activation: the balloon model," Magn. Reson. Med. 39(6), 855-864 (1998).

8. R. B. Buxton and L. R. Frank, "A model for the coupling between cerebral blood flow and oxygen metabolism during neural stimulation," J. Cereb. Blood Flow Metab. 17(1), 64-72 (1997).

9. P. T. Fox and M. E. Raichle, "Focal physiological uncoupling of cerebral blood flow and oxidative metabolism during somatosensory stimulation in human subjects," Proc. Natl. Acad. Sci. U. S. A. 83(4), 1140-1144 (1986).

10. H. Fujita et al., "Oxygen consumption of cerebral cortex fails to increase during continued vibrotactile stimulation," J. Cereb. Blood Flow Metab. 19(3), 266-271 (1999).

11. M. Vafaee and A. Gjedde, " $\mathrm{CMRO}_{2}-\mathrm{CBF}$ changes by finger motion: No evidence of flow-metabolism coupling in putamen," NeuroImage 13(6 Suppl.), 1012 (2001).

12. M. E. Raichle, "Behind the scenes of functional brain imaging: a historical and physiological perspective," Proc. Natl. Acad. Sci. U. S. A. 95(3), 765-772 (1998).

13. M. Mahmoudzadeh et al., "Syllabic discrimination in premature human infants prior to complete formation of cortical layers," Proc. Natl. Acad. Sci. 110(12), 4846-4851 (2013).

14. M. Mahmoudzadeh et al., "Functional maps at the onset of auditory inputs in very early preterm human neonates," Cereb. Cortex (2016).

15. F. Y. Wong et al., "Dopamine therapy promotes cerebral flow-metabolism coupling in preterm infants," Intensive Care Med. 35(10), 17771782 (2009).

16. C. E. Shannon, "A mathematical theory of communication," Bell Syst. Technol. J. 27(3), 379-423 (1948).

17. B. Gourevitch and J. J. Eggermont, "Evaluating information transfer between auditory cortical neurons," J. Neurophysiol. 97(3), 2533-2543 (2007).

18. N. Wiener, "The theory of prediction," in Modern Mathematics for Engineers, E. Beckenbach, Ed., McGraw-Hill, New York (1956).

19. M. Wolf and G. Greisen, "Advances in near-infrared spectroscopy to study the brain of the preterm and term neonate," Clin. Perinatol. 36(4), 807-834 (2009).

20. T. Durduran et al., "Optical measurement of cerebral hemodynamics and oxygen metabolism in neonates with congenital heart defects," J. Biomed. Opt. 15(3), 037004 (2010). 
21. N. Roche-Labarbe et al., "Noninvasive optical measures of $\mathrm{CBV}, \mathrm{StO}_{2}$, $\mathrm{CBF}$ index, and $\mathrm{rCMRO}_{2}$ in human premature neonates' brains in the first six weeks of life," Hum. Brain Mapp. 31(3), 341-352 (2010).

22. M. Nourhashemi, M. Mahmoudzadeh, and F. Wallois, "Thermal impact of near-infrared laser in advanced noninvasive optical brain imaging," Neurophotonics 3(1), 015001 (2016).

23. D. A. Boas and S. J. Payne, "Comment on "Estimating a modified Grubb's exponent in healthy human brains with near infrared spectroscopy and transcranial Doppler'," Physiol. Meas. 30(10), L9-L11 (2009).

24. T. S. Leung et al., "Estimating a modified Grubb's exponent in healthy human brains with near infrared spectroscopy and transcranial Doppler," Physiol. Meas. 30(1), 1-12 (2009).

25. M. A. Franceschini et al., "Assessment of infant brain development with frequency-domain near-infrared spectroscopy," Pediatr. Res. 61(5 Pt 1), 546-551 (2007).

26. O. B. Paulson, S. Strandgaard, and L. Edvinsson, "Cerebral autoregulation," Cerebrovasc. Brain Metab. Rev. 2(2), 161-192 (1990).

27. S. J. Matcher et al., "Absolute quantification methods in tissue nearinfrared spectroscopy," Proc. SPIE 2389, 486-495 (1995).

28. J. P. Culver et al., "Diffuse optical tomography of cerebral blood flow, oxygenation, and metabolism in rat during focal ischemia," J. Cereb. Blood Flow Metab. 23(8), 911-924 (2003).

29. H. M. Watzman et al., "Arterial and venous contributions to near-infrared cerebral oximetry," Anesthesiology 93(4), 947-953 (2000).

30. S. Wray et al., "Characterization of the near infrared absorption spectra of cytochrome aa3 and haemoglobin for the non-invasive monitoring of cerebral oxygenation," Biochim. Biophys. Acta 933(1), 184-192 (1988).

31. T. L. Davis et al., "Calibrated functional MRI: mapping the dynamics of oxidative metabolism," Proc. Natl. Acad. Sci. U. S. A. 95(4), 1834-1839 (1998).

32. T. Schreiber, "Measuring information transfer," Phys. Rev. Lett. 85(2), 461-464 (2000).

33. P. L. Madsen et al., "Cerebral $\mathrm{O}_{2}$ metabolism and cerebral blood flow in humans during deep and rapid-eye-movement sleep," J. Appl. Physiol. 70(6), 2597-2601 (1991).

34. A. M. Lam et al., "Change in cerebral blood flow velocity with onset of EEG silence during inhalation anesthesia in humans: evidence of flowmetabolism coupling?" J. Cereb. Blood Flow Metab. 15(4), 714-717 (1995).

35. R. L. Grubb et al., "The effects of changes in $\mathrm{PaCO}_{2}$ cerebral blood volume, blood flow, and vascular mean transit time," Stroke 5(5), 630-639 (1974).
36. L. Sokoloff et al., "The [14C]deoxyglucose method for the measurement of local cerebral glucose utilization: theory, procedure, and normal values in the conscious and anesthetized albino rat," J. Neurochem. 28(5), 897-916 (1977).

37. B. M. Cohen et al., "Abnormalities of regional distribution of cerebral vasculature in schizophrenia detected by dynamic susceptibility contrast MRI," Am. J. Psychiatry 152(12), 1801-1803 (1995).

38. D. Malonek et al., "Vascular imprints of neuronal activity: relationships between the dynamics of cortical blood flow, oxygenation, and volume changes following sensory stimulation," Proc. Natl. Acad. Sci. 94(26), 14826-14831 (1997).

39. S. A. Sheth et al., "Spatiotemporal evolution of functional hemodynamic changes and their relationship to neuronal activity," J. Cereb. Blood Flow Metab. 25(7), 830-841 (2005).

40. W. Kuschinsky and O. B. Paulson, "Capillary circulation in the brain," Cerebrovasc. Brain Metab. Rev. 4(3), 261-286 (1992).

41. B. Cauli and E. Hamel, "Revisiting the role of neurons in neurovascular coupling," Front. Neuroenerg. 2, 9 (2010).

42. A. F. McCaslin et al., "In vivo 3D morphology of astrocyte-vasculature interactions in the somatosensory cortex: implications for neurovascular coupling," J. Cereb. Blood Flow Metab. 31(3), 795-806 (2011).

43. G. Greisen, "Cerebral blood flow in preterm infants during the first week of life," Acta Paediatr. Scand. 75(1), 43-51 (1986).

44. R. W. Baumgartner, Handbook on Neurovascular Ultrasound, S. Karger AG, Basel, Switzerland (2006).

45. W. Kuschinsky, "Coupling of function, metabolism, and blood flow in the brain," Neurosurg. Rev. 14(3), 163-168 (1991).

46. O. B. Paulson et al., "Cerebral blood flow response to functional activation," J. Cereb. Blood Flow Metab. 30(1), 2-14 (2010).

47. M. Mahmoudzadeh et al., "Consequence of intraventricular hemorrhage on neurovascular coupling evoked by speech syllables in preterm neonates" (2016), under revision.

48. H. Uchino et al., Neuroanesthesia and Cerebrospinal Protection, Springer, Japan (2015).

49. Y. Kuroda et al., "Blood flow velocity of middle cerebral artery during prolonged anesthesia with halothane, isoflurane, and sevoflurane in humans," Anesthesiology 87(3), 527-532 (1997).

Biographies for the authors are not available. 